\title{
The Effectiveness and Relative Importance of Choice in the Classroom
}

\author{
Erika A. Patall \\ The University of Texas at Austin
}

\author{
Harris Cooper and Susan R. Wynn \\ Duke University
}

\begin{abstract}
This investigation examined the effects of providing choices among homework assignments on motivation and subsequent academic performance. Students were randomly assigned within classrooms either to receive a choice of homework options or to be assigned an option for all homework in one instructional unit. Conditions were reversed for a second instructional unit. Results revealed that when students received a choice of homework they reported higher intrinsic motivation to do homework, felt more competent regarding the homework, and performed better on the unit test compared with when they did not have a choice. In addition, a trend suggested that having choices enhanced homework completion rates compared with when no choices were given. In a second analysis involving the same students, the importance of perceived provision of choice was examined in the context of student perceptions of their teachers' support for autonomy more broadly defined. Survey data showed that the relationship between perceptions of receiving autonomy support from teachers and intrinsic motivation for schoolwork could be fully accounted for by students' perceptions of receiving choices from their teachers. The limitations and implications of the study for research and practice are discussed.
\end{abstract}

Keywords: choice, autonomy support, motivation, homework, classroom practices

Many North Americans believe that having choice, or the power to make a selection among a number of options, is essential in order to lead a healthy and happy life, to express individuality, and to maintain motivation for a broad variety of behaviors. Likewise, the role of choice has an important place in psychological theory. According to self-determination theory (Deci \& Ryan, 1985; Ryan \& Deci, 2000), choice is one of several determinants central to supporting feelings of autonomy, motivation, and healthful functioning. Research has supported these notions, showing that having choice is related to adaptive motivation and performance outcomes (Cordova \& Lepper, 1996; Iyengar \& Lepper, 1999; Patall, Cooper, \& Robinson, 2008; Swann \& Pittman, 1977; Zuckerman, Porac, Lathin, Smith, \& Deci, 1978).

It should come as no surprise then that the beliefs and practices of many teachers may reflect a belief in the value of choice. A phenomenological study of teachers' beliefs about choice suggested that allowing students options in their instruction was a popular method by which teachers attempted to enhance student motivation and learning (Flowerday \& Schraw, 2000). In this study, teachers reported believing that providing students with choices increases student interest, engagement, and learning; that

This article was published Online First September 20, 2010.

Erika A. Patall, Department of Educational Psychology, The University of Texas at Austin; Harris Cooper, Department of Psychology and Neuroscience, Duke University; Susan R. Wynn, Program in Education, Duke University.

We thank Kate Seibert, Erica Fritz, Matthew Saternus, Jeffrey Faulring, John Nejman, and Marissa McDaniel for their assistance with conducting this research.

Correspondence concerning this article should be addressed to Erika A. Patall, Department of Educational Psychology, The University of Texas at Austin, One University Station, D5800, Austin, TX 78712-0383. E-mail: erika.patall@mail.utexas.edu students spend more time and effort on the learning task if they are offered choices; and that giving students choices helps build other important skills, such as self-regulation. In particular, teachers suggested that choice was especially beneficial for students with low interest and little motivation for a particular task. With regard to when to offer choice, teachers suggested a variety of academic and social activities in which providing choices would benefit students. One of these was homework.

Despite the evidence regarding teachers' intuitive beliefs and numerous laboratory studies showing the beneficial effects of choice on motivation and learning, few studies have examined the impact of choice in a naturally occurring classroom setting. Thus, it is difficult both to assess whether choice is practically effective and to make recommendations to teachers regarding how choice may be used most profitably in their classes. Moreover, providing choice to students is just one of many techniques theorists have suggested might support feelings of autonomy and, in turn, motivation and learning (Assor, Kaplan, \& Roth, 2002; Reeve, 2006; Reeve \& Jang, 2006; Stefanou, Perencevich, DiCintio, \& Turner, 2004). Assuming the beneficial effects of having choices, little is known about the relative contribution of providing students with choices at school within the broader context of other teaching practices meant to support a student's sense of autonomy and to enhance motivation.

This study was undertaken to test the utility of applying choice in the classroom. In the first analysis, we examined the causal impact of choice within a particular pedagogical strategy, namely, homework. Specifically, we tested whether providing a choice of homework assignments facilitated learning outcomes, including greater intrinsic motivation and perceived competence, as well as enhanced homework performance and academic achievement. In a second analysis, we sought to shed light on the relative importance of receiving choices at school in the context of other teacher practices proposed to support autonomy. Cross-sectional survey 
data assessing students' naturally occurring perceptions of their experiences at school was used to test whether the relationship between perceptions of teacher practices meant to support autonomy and intrinsic motivation for schoolwork could be fully accounted for by students' perceptions of the extent to which their teachers at school provide opportunities to make choices. The background, methods, and results for each of the two analyses are discussed separately and in turn. We first turn to background information related to the effectiveness of providing homework choices in the classroom.

\section{Homework Choices}

\section{The Value of Homework}

Homework is an important part of most students' daily routine. According to a recent survey (Markow, Kim, \& Liebman, 2007), regardless of grade level, three quarters of students reported being assigned homework at least three days a week and spending at least 30 minutes on homework on a typical school day. Further, over $80 \%$ of teachers and parents, and $77 \%$ of students agreed that doing homework is important or very important. Likewise, around $90 \%$ of teachers and parents, and $69 \%$ of students supported the belief that homework can help students to learn more in school.

A great deal of research has examined the relationship between homework and academic achievement. More than a dozen reviews of the homework literature were conducted between 1960 and 1987 (see Cooper, 1989, for a detailed description), and the conclusions of these reviews varied greatly, due, in part, to a lack of overlap in the literature they covered, to different criteria for inclusion of studies, and to different methods for the synthesis of study results. However, the most recent quantitative reviews have suggested that homework has benefits for academic achievement. Two meta-analyses examining the link between homework and achievement provided consistent evidence for a positive overall relationship, especially for high school students. Cooper (1989) carried out a review of the effects of homework, which covered nearly 120 empirical studies conducted between 1962 and 1986. This synthesis revealed that high school students who did homework outperformed students who did not do homework, and students who reported spending more time on homework had better achievement outcomes. Cooper, Robinson, and Patall (2006) recently updated this synthesis and found that the positive overall relationship between homework and achievement for high school students remained supported in both experimental and correlational studies.

Apparently, then, homework can have a significant impact on high school students' educational trajectories. However, it is also the case that not all teachers assign homework and/or not all students complete the homework they are assigned. According to the Markow et al. (2007) survey, one quarter of students reported that they finished their homework only sometimes, rarely, or never. This suggests that whatever impact homework might have on achievement might vary from student to student, depending on how much they are assigned or how much they complete. Therefore, an important question arises regarding how teachers can encourage students to undertake their homework in a diligent manner.

\section{Intrinsic Motivation}

One potential explanation for incomplete homework assignments may involve the student's motivation. For certain students, homework assignments and other school-related work may be of little intrinsic interest in that they derive little enjoyment from performing the activity (Trautwein \& Koller, 2003). Therefore, if intrinsic motivation to perform homework can be improved, then more frequent and accurate assignment completion and improved academic achievement should follow.

Intrinsic motivation is the propensity to engage in a behavior for its own sake (or out of enjoyment; Deci, 1971). Intrinsic motivation has been linked with academic outcomes across various levels of education, from elementary school to college (Grolnick, Ryan, \& Deci, 1991; Lepper, Corpus, \& Iyengar, 2005; Pintrich \& De Groot, 1990; Miserandino, 1996; Vallerand \& Bissonnette, 1992; Vallerand, Fortier, \& Guay, 1997). For example, elementary school students who reported greater intrinsic motivation for performing schoolwork displayed greater conceptual learning and memory compared with students with less intrinsically oriented forms of motivation (Grolnick \& Ryan, 1987). Significant correlations also have been found between intrinsic motivation and achievement as measured by standardized achievement tests in specific subjects, such as mathematics and reading for early elementary, late elementary, and junior high school students (Gottfried, 1985, 1990).

\section{Self-Determination Theory and Choice}

According to self-determination theory, autonomy, competence, and relatedness are three fundamental needs that underlie people's intrinsic motivation (Deci, 1971), and social contexts that satisfy these needs will enhance intrinsic motivation (Ryan \& Deci, 2000). Therefore, intrinsic motivation is enhanced when an individual feels autonomous and when information is provided about the individual's competence in navigating his or her environment In contrast, when the environment is experienced as controlling, autonomy and intrinsic motivation are diminished (Deci, Connell, \& Ryan, 1989).

Providing choice may be the most obvious way to support a person's experience of autonomy. As such, self-determination theory holds that choice should result in positive motivational and performance outcomes (Deci, 1980; Deci \& Ryan, 1985; Ryan \& Deci, 2000). That is, people will be more intrinsically motivated to persist at a task to the extent that the activity involves their personal choice and/or provides opportunities to make choices.

Much research has supported this postulate of selfdetermination theory, demonstrating that the provision of choice leads to enhanced motivation, liking, and interest for a task (Cordova \& Lepper, 1996; Iyengar \& Lepper, 1999; Swann \& Pittman, 1977; Zuckerman, Porac, Lathin, Smith, \& Deci, 1978), as well as enhanced effort, task performance, subsequent learning, and perceived competence (Cordova \& Lepper, 1996; Iyengar \& Lepper, 1999). For example, Iyengar and Lepper (1999) found that Caucasian American elementary school students performed best when they made personal choices about which tasks to engage in, rather than having the task chosen for them. Similarly, children provided with choices demonstrated greater learning, as measured by the number of problems answered correctly on a math test, compared 
with when choices were not provided (Cordova \& Lepper, 1996). Moreover, there is some evidence to suggest that the positive effects of choice remain even for choices that appear trivial (Cordova \& Lepper, 1996; Swann \& Pittman, 1977) or "illusory" (Langer, 1975).

However, the evidence on choice effects has not been ubiquitously positive. Some studies have found that choice may have no effect or even a negative effect on motivation and performancerelated outcomes (Overskeid \& Svartdal, 1996; Parker \& Lepper, 1992; Reeve, Nix \& Hamm, 2003). Iyengar and Lepper (1999) found that Asian American elementary school students demonstrated greater intrinsic motivation and performance on a task when a significant other, their mother, made choices for them compared with when they made choices for themselves. In a series of studies, Flowerday and colleagues (Flowerday \& Schraw, 2003; Flowerday, Schraw, \& Stevens, 2004) found that choice had few positive effects. For example, giving students a choice between working on a crossword puzzle or essay task showed no effect on engagement and task performance and a negative effect on effort (Flowerday \& Schraw, 2003). In a second study, students allowed to choose the pacing of the task spent less time studying and performed more poorly on cognitive measures compared with students whose pace was dictated by the experimenter (Flowerday $\&$ Schraw, 2003). In two additional studies, no-choice participants were found to write higher quality essays compared with students who were given choice. Choice had no effect on a subsequent test to assess learning (Flowerday et al., 2004).

Motivation theorists have attempted to resolve the discrepancies in findings. In a narrative review examining when choice had motivational benefits and when it did not, Katz and Assor (2007) suggested that choice may only be effective when it successfully satisfies fundamental needs for autonomy, competence, and relatedness. As such, having choice or the act of selecting alone is not enough to support motivation. Rather, choices need to be relevant to students' interests and goals, provide a moderate number of options of an intermediate level of complexity, and be congruent with other family and cultural values in order to effectively support motivation. The authors provide examples to show that in investigations in which the provision and perception of having choice was beneficial, these components were taken into consideration. In another attempt to resolve discrepancies, a recent meta-analysis of 41 studies examining the effect of choice on intrinsic motivation and related outcomes in a variety of settings indicated that overall, providing choice compared with no choice indeed enhanced intrinsic motivation, effort, task performance, and perceived competence, among other outcomes (Patall, Cooper, \& Robinson, 2008). Results of this meta-analysis suggested that the effects of choice were particularly pronounced among studies conducted with children compared with those with adults. This suggests that providing choices to students in a classroom setting may be a particularly effective way to enhance motivation and other adaptive learning outcomes for school tasks, although few if any studies have experimentally examined the impact of choice in a naturally occurring classroom setting. Further, to the extent that homework options are designed at an optimal level of complexity and allow students to actualize their personal interests and goals, the assertions of Katz and Assor (2007) suggested that providing students with choices of homework may be a good example of how choice can be utilized to promote adaptive outcomes in the classroom.

\section{Purpose of Analysis 1}

Whereas a great deal of evidence suggests that providing individuals with choice enhances motivation and other adaptive learning outcomes (Patall et al., 2008), little research has empirically examined the utility of providing choices in naturally occurring classrooms within a specific pedagogical practice. To address this omission, we experimentally manipulated the use of choice in the context of homework assignments. In line with self-determination theory and previous research, we predicted that when students are provided with choices of homework, enhanced intrinsic motivation will result relative to when no choices of homework are provided. Intrinsic motivation was the main focus, as it is theorized to represent the ideal form of autonomous motivation that most successfully sustains enduring engagement and other adaptive outcomes. As such, providing choices was expected to increase homework completion and improve subsequent academic achievement, among other adaptive outcomes. We now turn to background information related to the role of choice in the context of other teacher practices intended to support feelings of autonomy and subsequent motivation.

\section{Perceived Choice in the Context of Perceptions of Broad Autonomy Support}

Providing choices is not the only way to support the experience of autonomy and intrinsic motivation. Autonomy is experienced when actions are perceived as (a) stemming from an internal locus of causality or individuals' perceptions that their actions are initiated and controlled by them rather than by external forces (deCharms, 1968), (b) volitional, or the sense that individuals feel free rather than forced to engage in a behavior, and (c) chosen and performed out of interest or personal importance (Deci \& Ryan, 1987). Consequently, in addition to choice, teacher practices that may also support feelings of autonomy include (a) listening carefully, (b) gearing instruction to students' interests and personal preferences, (c) expressing value for tasks and providing rationales for activities, (d) using noncontrolling language, (e) providing opportunities for and responses to questions and comments, and (f) acknowledging students' perspectives, among other behaviors (Reeve, 2006; Stefanou et al., 2004).

Teaching practices meant to support feelings of autonomy have also been linked to greater intrinsic motivation, as well as subsequent learning-related outcomes (Deci, Schwartz, Sheinman, \& Ryan, 1981). For example, Reeve, Jang, Carrell, Jeon, and Barch (2004) found that students were more engaged when teachers used various autonomy-supportive practices during instruction, such as nurturing inner motivational resources, using noncontrolling language, promoting valuing, and acknowledging and accepting negative affect. Black and Deci (2000) found students' perceptions of their instructors as supportive of autonomy predicted increased autonomous self-regulation, perceived competence, interest/ enjoyment, and decreased anxiety over the semester. Other research has shown that social contexts meant to support feelings of autonomy were associated with better conceptual learning (Grolnick \& Ryan, 1987), more creativity (Koestner, Ryan, Berni- 
eri, \& Holt, 1984), and more positive affect (Deci, Hodges, Pierson, \& Tomassone, 1992; Ryan \& Grolnick, 1986) as compared with less autonomy-supportive social contexts.

In fact, a number of researchers have proposed that many of these other autonomy-supportive practices may be more effective than providing choice alone in supporting motivation and learning either individually or collectively. Stefanou et al. (2004) categorized practices meant to support feelings of autonomy into three categories: organizational, procedural, and cognitive. They theorized that whereas organizational supports (e.g., allowing students some decision-making role in terms of classroom management issues) and procedural supports (e.g., offering students choices about the use of different media to present ideas) are beneficial in supporting well-being and initial engagement in learning activities, support for cognitive autonomy (e.g., affording opportunities for students to evaluate work from a self-referent standard) may be most effective for promoting enduring engagement and deep-level thinking.

In models exploring the nature of perceived autonomy (or self-determination) and its relation to intrinsic motivation, Reeve et al. (2003) found that internal locus and volition, but not perceived choice, constituted valid indicators of self-determination. Through structural equation models, these authors compared a series of models containing one, two, or all three qualities of perceived self-determination to find the best fitting model. The inclusion of perceived choice was consistently found to reduce the fit of the model and reduced the strength of the relationship between perceived self-determination and intrinsic motivation.

Similar findings were reported by Assor et al. (2002) when they distinguished among three forms of autonomy-supportive teacher practices: fostering relevance by articulating the importance of a task for students' personal goals, allowing students to express dissatisfaction with learning tasks, and providing opportunities to make choices. They found that whereas allowing students to express their concerns if they do not like a task and fostering the relevance of a task promoted engagement, perceptions of provision of choice had little impact.

Nevertheless, providing choice may be one of several ways teachers can influence multiple sources of autonomy with one interaction. That is, when a student perceives that their teacher allows them to make choices, this may also increase the students' perceptions that the teacher is listening to them, taking their perspectives into consideration, and understanding or respecting them. Consequently, allowing students to act as decision makers in their own education may be the most direct way to establish an environment that is supportive of autonomy and enhance intrinsic motivation for school-related tasks. This may be particularly the case when the choices provided are intentionally designed to support the fundamental needs for autonomy, competence, and relatedness. Similarly, choice may be more likely to imply multiple forms of autonomy support when the options provided are designed to simultaneously support an internal locus of causality and volition. Reeve et al. (2003) suggested this perspective. These authors found that whereas choices between task options had little influence on intrinsic motivation, choices that involved making decisions regarding the initiation of behavior did influence motivation. The researchers speculated that these types of choices also enhance perceptions of having an internal locus of causality and volition.
Whereas the perception of having opportunities for making choices has the potential to tap into other components of autonomy support, in contrast, it may be more difficult for other practices that support autonomy to enhance the perception of choice. For example, simply because a student perceives that their teachers actively listen, provide rationales, or communicate that they understand the student's perspectives does not necessarily suggest that the student perceives having opportunities to make choices within the classroom. However, effectively designed choices that support the fundamental needs, an internal locus of causality, and/or volition do imply the other forms of autonomy support. Further, when teachers provide students with choices, this concrete behavior may be easily and accurately perceived by the student. In contrast, even when a teacher is actively engaging in a number of other forms of autonomy-supportive behavior, including listening, perspective taking, or rationale providing, these behaviors may be nebulous and may not be readily perceived by students, diminishing their potential impact.

\section{Purpose of Analysis 2}

The second part of this study attempts to examine the relative benefits of students' perceptions of having been provided with choices from teachers at school in the context of their perception of other teacher practices that support feelings of autonomy. As previously discussed, a student will feel autonomous and motivated when he or she feels that their teachers understand, accept, and respect them in the classroom, provide rationales, take their perspectives, and tailor activities to their interests and preferences, among other behaviors. Because we expect that students' perception of having been provided choice will simultaneously support their perception of other autonomy-supportive teacher behaviors, we hypothesized that choice may be the most direct means by which to enhance feelings of autonomy. Consequently, we hypothesized that perceived provision of choice will fully account for any relationship between motivation and students' perceptions of receiving other forms of autonomy support from their teachers. That is, we are not proposing that perceptions of being provided with choice is the mechanism through which perceptions of other autonomy supportive practices have their impact in a traditional mediation sense. Rather, working with the notion that perceptions of perceived choice can have broad implications for feelings of autonomy and motivation, we use analytic procedures similar to those used to assess a meditational framework in order to examine the role of perceived choice in the context of and in comparison with perceptions of other autonomy-supportive practices. In essence, we are asking the question of whether perceived provision of choice can subsume the effect of perceiving other forms of autonomy support on motivation.

\section{Method}

\section{Participants}

A total of 207 (54\% female) high school students from grades 9 through 12 participated in this study. Participants were from 14 classrooms at two urban high schools in a southeastern state. Approximately $68 \%$ of students in these 14 classes participated in the study. The 14 classrooms had one of six preservice teachers 
who were completing their required teaching internship. The preservice teachers prepared and administered the experimental treatments as part of their research requirement for the certification program, after receiving training from the first author. Six different courses were used: chemistry, honors world history, honors U.S. history, psychology, honors earth science, and advanced placement U.S. government. A majority $(55.5 \%)$ of the students in these classes were Caucasian, 28\% were African American, 7\% were Asian, $3 \%$ were Hispanic, $1.5 \%$ were Native American, and 5\% were of other ethnicities. Participation was voluntary for students who had been given parental permission. Whereas a total of 207 students participated in this study at one or more time points, the number of students contributing information varied depending on the outcome of interest.

\section{Procedure}

The experiment was implemented over four weeks. During the first session, preservice teachers administered a background and school experiences questionnaire to all participating students in their classes. This questionnaire included questions regarding the student's (a) sex, (b) ethnicity, (c) grade point average (GPA), (d) experience of choice in their classes at school, (e) experiences of autonomy support in their classes at school, (f) perceptions of their own competence for doing schoolwork, and (g) self-regulatory reasons for doing various types of schoolwork. The information obtained in this questionnaire was used in Analysis 2 in order to address questions related to the role of the student's perceptions of teachers providing them with choice in the context of perceptions of other autonomy-supportive teacher practices.

The homework-choices experimental manipulation was initiated in the second session. This session occurred at the start of the first of two instructional units. During this session, the preservice teachers randomly assigned students within each of their classes to either a homework-choice or no-homework-choice condition for the first phase of the study. Random assignment was accomplished by student teachers drawing students' names out of a hat to determine which students would be assigned to the homeworkchoice and no-homework-choice conditions during the first unit.

Students in the homework-choice condition were given a list of two similar homework assignment options designed by the preservice teacher. Students were instructed to select which homework assignment they intended to complete. Preservice teachers then assigned students in the no-homework-choice condition to one of the homework options by yoking each no-homework-choice student to a student in the homework-choice condition. Students in the no-homework-choice condition were not yoked to a particular individual in the homework-choice condition across every homework assignment in the unit. The particular individuals in the yoked dyad could vary from one homework assignment to the next. We avoided yoking particular individuals because we did not want this to create an environment in which it became apparent to students that the selections a particular classmate in the homework-choice condition made determined the homework options a student in the homework-no-choice condition received. What was important was that an equal number of students in both conditions completed each homework option for every assignment.

At a practical level, the experimental manipulation required that student teachers go around the room, student by student, and record which homework choice students selected and then assign no-homework-choice students the corresponding options. This process began with a student in the homework-choice condition (so that a no-choice student could be yoked). However, the student teacher went intermittently between students in the choice condition and students in the no-choice condition to record the homework selection or assignment of each student. Several students in each condition were visited in a row so that no-homework-choice students would not suspect they were yoked to a particular classmate in the homework-choice condition. This procedure provided the best way to limit in-class contamination without extensively disrupting regular classroom proceedings. That is, student teachers essentially had a private conversation (though, in class) with each student separately in order to determine homework assignments. This limited the extent to which other students were privy to the conditions, selections, and assignments of classmates. As an additional attempt to limit contamination between conditions, student teachers also emphasized to students that they should avoid discussing what homework they selected or were assigned with classmates while the study was being conducted.

Once students made their homework selections or received their assignment, written homework instructions were distributed. In many cases, the homework was a separate worksheet that the student teacher had created, and this was distributed. In those cases in which the homework was completed out of a textbook or required no additional materials from the student teacher, students only received written instructions on what was required for the homework they selected or were assigned. Students were instructed to complete only the assignment they had selected or were assigned. Although students in the homework-choice condition had viewed information on both homework options in order to select one, once students made their selections, they were allowed to keep only written instructions related to their selected homework and not other homework options. The deadline by which students had to complete homework was indicated on the written homework instructions or homework worksheet. The deadline by which students had to turn in a homework assignment was the same regardless of what homework option was selected or assigned.

This procedure was repeated for every homework assignment completed during that unit. At the end of the first unit, preservice teachers administered the Intrinsic Motivation Inventory (Ryan, 1982) to all students in both the homework-choice and nohomework-choice conditions.

At the beginning of the next unit of study, the same procedure was implemented a second time after counterbalancing the conditions in which students participated. That is, students who had previously received a choice of homework assignments were reassigned to the no-homework-choice group. Conversely, students who were previously assigned homework were given a choice of homework. At the end of this second unit of instruction, the Intrinsic Motivation Inventory was administered a second time. The purpose of this procedure was (a) to demonstrate the choice effect within the individual and (b) to afford all students in the class the opportunity to experience the homework-choice condition.

The number of homework assignments preservice teachers required in each unit ranged between one and five $(M=2.3)$, and the length of an instructional unit ranged between one and two weeks 
across the various classes. The frequency with which each homework option was selected varied with the homework assignment and between classes. That is, even for students making a choice between the same homework options for the same course, the frequency with which one homework option was chosen over the other varied such that the favored option in one class may not have been the favored option in a corresponding class taking the same course with the same teacher. Nevertheless, on average, across the 28 different homework tasks (two options for each task) across all courses, one homework option was usually slightly preferred, with approximately $60 \%$ of students selecting one homework option over the other option for most homework assignments (preference for a particular homework option ranged between $57 \%$ and $87 \%$ depending on the particular homework task). Regardless, we addressed any effect of preference for a particular homework assignment by using the yoking procedure described.

\section{Materials}

Background questionnaire. The background questionnaire included questions regarding the student's gender, ethnicity, and self-reported grade point average.

School experiences questionnaire. The school experiences questionnaire consisted of five measures related to motivation: the Provision of Choice subscale of the Rochester Assessment Package for Schools (Connell, 1990; Wellborn \& Connell, 1987), the Learning Climate Questionnaire (Williams \& Deci, 1996), three items assessing perceived competence from the Activity-Feelings Scale (Reeve \& Sickenius, 1994), and the Intrinsic Motivation and Identified Regulation subscales of the Academic Self-Regulation Questionnaire (Ryan \& Connell, 1989).

The Provision of Choice subscale of the Rochester Assessment Package for Schools is a seven-item scale assessing the degree to which students perceive that they are given choices by their teachers (e.g. "My teachers ask us which topics we would like to study more and which we prefer to study less"). We added one additional item to this scale to provide a very explicit measure of the provision of choice: "I feel that my instructors provide me with choices and options." All items used a Likert-type scale ranging from 1 (not true at all) to 7 (very true).

The Learning Climate Questionnaire is a 15 -item scale that measures the degree to which students perceive their teachers at school as supportive of autonomy because, for example, they feel that their teachers listen, understand, encourage, care about and accept them, and answer questions, and they trust their teachers (e.g. "I feel understood by my teachers" or "My teachers encourage me to ask questions"). All items were rated on a Likert-type scale ranging from 1 (strongly disagree) to 7 (strongly agree). Previous studies have established the validity of the Learning Climate Questionnaire and the observation that the scale has a single underlying factor, with high internal consistency generally found to be above .90 (Williams \& Deci, 1996; Black \& Deci, 2000).

We examined the perceived choice and Learning Climate Questionnaire scales in an exploratory factor analysis to determine whether these scales could be used to reliably assess distinguishable constructs. In an initial exploratory analysis using principal axis extraction with oblique rotation, we found three items from the Learning Climate Questionnaire to be problematic in that they demonstrated overlap with the perceived provision of choice scale
("I feel that my teachers provide me choices and options"; "My teachers listen to how I would like to do things"; and "My teachers try to understand how I see things before suggesting a new way to do things"). These three items were removed and the remaining items were submitted to principal axis extraction with oblique rotation, forcing a two-factor solution. Results of the KaiserMeyer-Olkin measure of sampling adequacy $(K M O=.91)$ suggested that the data were indeed suitable for factor analysis. Likewise, Bartlett's test of sphericity, $\chi^{2}(190)=1,769.37, p<$ .001 , indicated that the items were significantly correlated in order to proceed with the analysis. The two factors explained $49.66 \%$ of the total variance for the set of variables. Using a criterion of a factor loading greater than or equal to .40 , we found that all items from the Learning Climate Questionnaire loaded on Factor 1 (eigenvalue $=7.42$ ), which accounted for $37.08 \%$ of the variance. Likewise, all items from the perceived provision of choice scale loaded on Factor 2 (eigenvalue $=2.52$ ), which accounted for $12.58 \%$ of the variance. Consequently, we computed scores for the Learning Climate Questionnaire by taking the mean of the items after dropping the three problematic items initially excluded from the factor analysis. The scale had acceptable reliability $(\alpha=.92)$. Likewise, scores for the perceived provision of choice scale were computed by taking the mean of all items. This scale also demonstrated acceptable reliability $(\alpha=.81)$. Additional details regarding the exploratory factor analysis may be obtained from the authors.

Perceived competence was measured with three items from the Activity-Feelings Scale. Items from this scale begin with the stem: "When engaged in school-related tasks, I feel ..." The scale lists items to assess perceived competence include the following: "capable," "achieving," and "competent." The predictive validity, construct validity, and reliability of the scale have been established in previous studies, with the average internal consistency in previous research being $\alpha=.85$ (Reeve \& Robinson, 1987; Reeve \& Sickenius, 1994). In this study, items used a Likert-type scale ranging from 1 (not true at all) to 7 (very true), and the overall scale had high internal consistency $(\alpha=.85)$.

Students also completed two subscales adapted from the Academic Self-Regulation Questionnaire, which assessed student motivation toward education in terms of why they do homework, perform classwork, answer difficult questions in class, and try to do well in school. For the purposes of this study, only items for the Intrinsic Motivation and Identified Regulation subscales were included. Seven possible reasons representing these two different styles of regulation or motivation were provided for four activities homework, classwork, answering hard questions, and trying to do well in school. The Identified Regulation subscale represents an individual's intention to engage in the activity because it is personally valued or important (e.g. "Because I want to understand the subject"). The Intrinsic Motivation subscale represents an individual's intention to engage in the activity because it is interesting or enjoyable (e.g. "Because it's fun"). Ryan and Connell (1989) have presented extensive evidence for the construct validity of the scale and have demonstrated appropriate correlations with other motivation assessments. In this study, both subscales demonstrated adequate reliability (intrinsic motivation, $\alpha=.85$; identified regulation, $\alpha=.80$ ).

Intrinsic motivation inventory. The Intrinsic Motivation Inventory (Ryan, 1982) was administered twice, following the comple- 
tion of all homework at the end of each of the two units. The Intrinsic Motivation Inventory is a measure assessing multiple aspects of motivation. Thirty-four items from the measure were adapted to specifically refer to the homework assignments in the particular unit. The Intrinsic Motivation Inventory contains six subscales: interest/enjoyment of the task (seven items; Unit $1 \alpha=.85$; Unit $2 \alpha=$ .87) (e.g., "I enjoyed doing the homework very much"), perceived competence for the task (six items; Unit $1 \alpha=.87$; Unit $2 \alpha=.86$ ) (e.g., "I think I was pretty good at the homework"), effort on the task (five items; Unit $1 \alpha=.76$; Unit $2 \alpha=.82$ ) (e.g., "I tried very hard on the homework"), perceived value/usefulness of the activity (four items; Unit $1 \alpha=.81$; Unit $2 \alpha=$.79) (e.g., "I believe the homework could be of some value to me"), perceived pressure and tension felt while engaging in the task (five items; Unit $1 \alpha=.76$; Unit $2 \alpha=.71$ ) (e.g. "I felt very tense while doing the homework"), and perceived choice while performing the given activity (seven items; Unit $1 \alpha=$ .81; Unit $2 \alpha=.82$ ) (e.g., "I believe I had some choice about doing the homework"). The interest/enjoyment subscale is considered a self-report measure of intrinsic motivation, whereas all other subscales are considered to be motivation-related constructs (Ryan, 1982). Items on the Intrinsic Motivation Inventory used a Likert-type scale ranging from 1 (not true at all) to 7 (very true). McAuley, Duncan, and Tammen (1989) examined the validity of the Intrinsic Motivation Inventory and found support for its validity.

Homework assignments. With the help of the first author and the regular classroom teachers, preservice teachers developed two versions of each homework assignment they required during the two instructional units. Preservice teachers were instructed that the versions of each homework assignment should be identical in content and of an intermediate level of difficulty. Homework would then vary in terms of the method by which the material was learned. For example, a student might have had a choice of completing a crossword puzzle or a word search on important vocabulary words covered in their class or a choice between two sets of short answer questions on the same topic. In this way, homework options allowed students to choose a task that was reflective of their personal preferences, but the content learned and level of difficulty of the homework did not vary with the choice. The material covered in homework was determined by the preservice teachers in conjunction with the regular classroom teacher and in light of the required curriculum and needs of the students. Homework completion was recorded. Students submitted homework with their names on it and no indication about which condition they participated in.

Unit test scores. At the end of both units, preservice teachers administered a unit test to all students in their classes to assess proficiency with the material covered. These tests were designed and graded by the preservice teacher in collaboration with the regular classroom teacher. The design and administration of the unit tests were in no way dependent on this study. These were the same unit tests that would have been administered to evaluate students' understanding of the material from the unit regardless of whether the study took place. The structure and content of the unit tests varied depending on the course and content being covered during each particular unit of the course, as well as the preservice and regular teachers' testing approaches. The scores on unit tests were used as the post-manipulation measure of student academic performance.

\section{Results}

\section{Analysis 1: The Effect of Homework Choices}

Preliminary analyses. First, we examined the distribution of scores on each variable for statistical outliers. Post-manipulation assessments were examined within condition. Grubbs's (1950) test was applied and if outliers were identified, these values were set at the value of their next nearest neighbor. Grubbs's test was repeated after this substitution to detect any additional outliers. If additional outliers were detected, these values were again set to their next nearest neighbor. This procedure was repeated until no outliers were detected. This procedure revealed four outliers. Three outliers were found on the Unit 2 test: one in the choice condition (the outlier value of 18.00 was Winsorized to the next nearest value of 52.00) and two in the no-choice condition (both outliers had a value of 0 that was Winsorized to the next nearest value of 18). One outlier in the choice condition was found on the Unit 1 assessment of pressure or tension felt on the homework (the outlier value of 7.00 was Winsorized to the next nearest value of 6.00).

Data were regularly collected for the study across four weeks. Consequently, when a student was absent from school at any point during the course of the study, data for that student were missing. Specifically, $163(79 \%)$ of the 207 total students completed the Intrinsic Motivation Inventory following both units, 186 students (90\%) took both unit tests, and 201 students (97\%) completed the background and school experiences questionnaire, although only 177 students (86\%) provided information for every scale in both questionnaire packets. The homework completion variable reported by preservice teachers also had missing values (four missing and $98 \%$ complete).

To assess whether data were systematically missing, we computed a series of $t$ tests comparing students missing data at any time point with students for whom data were present at all time points on each variable. For tests in which the assumption of equal variances was violated, we used the adjusted $t$ statistic determined with individual sample standard deviations, rather than a pooled standard deviation, and the Satterthwaite approximation of the degrees of freedom was used.

Students who were missing information at any time point differed from students with complete data along a number of variables. Compared with students who had complete data, students who were missing data had lower self-reported overall GPA, $t(176)=2.06, p=.04$, lower test scores during both Unit 1 , $t(193)=2.20, p=.03$, and Unit $2, t(178)=4.99, p<.0001$, and lower Unit 2 homework completion rates, $t(188)=2.29, p=.02$. Therefore, across various measures of achievement, findings suggest that students missing data at any time point were lower achievers compared with students who had complete data. In addition, students missing data perceived less autonomy support from their teachers, $t(190)=2.66, p=.009$, and reported lower perceived competence prior to the experimental manipulation, $t(197)=3.04, p=.003$, as well as after the experimental manipulation during both Unit $1, t(187)=3.78, p=.0002$, and Unit 2, $t(177)=3.35, p=.001$. Chi-square tests suggested that there was no difference between students missing data compared with students who had complete data in terms of their gender, ethnicity or the experimental condition to which they were initially assigned. 
The impact of missing data was minimized by using the SAS procedure called PROC MIXED in the context of a multilevel modeling approach. Among other advantages, including the ability to appropriately model hierarchically nested data (which we discuss further below), one advantage of using this analysis strategy is that it utilizes all of the available data. However, caution must be taken in interpreting results, as the pattern of missing data may not be of a sort that can be disregarded, and results may not be generalizable to lower achieving students. ${ }^{1}$

Verification of comparability of treatment groups. To verify that there were no preexisting differences between students initially assigned to the homework-choice condition compared with students who were initially assigned to the no-homeworkchoice condition, we performed a series of independent $t$ tests for all baseline measures reported prior to the homework choices manipulation. There were no significant differences between the two groups on any baseline measure: for baseline perceived provision of choice, $t(197)=-0.47, p=.64$; for baseline perceived autonomy support, $t(197)=1.15, p=.25$; for baseline perceived competence, $t(196)=0.78, p=.44$; baseline intrinsic motivation, $t(196)=-0.72, p=.48$; for baseline identified regulation, $t(196)=1.10, p=.27 ;$ and for GPA, $t(176)=0.44, p=.66$.

Primary analyses. We used hierarchical linear modeling (HLM; Raudenbush \& Bryk, 2002) for our primary tests. HLM appropriately addressed the hierarchically nested design of our data set, in which lower level units (i.e., trials) were nested within a second higher level unit (i.e., students) and students were nested within a third higher level unit (i.e., classrooms). HLM treats student and classroom as a random rather than a fixed effect, thereby permitting generalizations of the findings to a wider population.

First, we calculated intraclass correlations (ICCs) attributable to class and attributable to student within class for each of the eight post-manipulation outcome variables. That is, we assessed the correlation between any two trials of students in the same class, $I C C_{\text {class }}$, as well as the correlation between any two trials for the same student in a class, $I C C_{\text {student(class) }}$. In the unconditional model, each outcome variable is based only on an intercept term and error terms, with no predictors or covariates included in the model. The ICCs suggested that an HLM approach would provide an advantage over a standard fixed-effects model approach for the analysis of this data: for post-manipulation perceived choice: $I C C_{\text {student(class) }}=.65$, for $I C C_{\text {class }}=.03$; for post-manipulation interest/enjoyment: $I C C_{\text {student(class) }}=.64, I C C_{\text {class }}=.03$; for post-manipulation perceived competence: $I C C_{\text {student(class) }}=.59, I C C_{\text {class }}=.13$; for postmanipulation effort: $I C C_{\text {student(class) }}=.51, I C C_{\text {class }}=.03$; for post-manipulation value: $I C C_{\text {student(class) }}=.69, I C C_{\text {class }}=.09$; for post-manipulation pressure/tension: $I C C_{\text {student(class) }}=.53, I C C_{\text {class }}=$ .10 ; for homework completion rate: $I C C_{\text {student(class) }}=.30, I C C_{\text {class }}=$ .05 ; and for unit test score: $I C C_{\text {student(class) }}=.37, I C C_{\text {class }}=.01$. The variance component for student $\left(\tau_{00}^{(2)}\right)$ was significant in the unconditional model for every outcome variable. However, the variance component for class $\left(\tau_{00}^{(3)}\right)$ was not significant for any of the outcome variables, except perceived competence. Nevertheless, we decided to retain this term in the model for several reasons. First, the nonsignificance of the test may simply be due to lower power (with 14 classes). Second, the inclusion of this term is consistent with the data structure and did not produce any estimation difficulties. The results of these unconditional hierarchical linear models are summarized in Tables 1 , 2 , and 3 .

Next, to assess whether the homework choice manipulation had affected students' perceptions and behavioral outcomes (see Table 4 for means and standard deviations for each outcome variable by condition), we ran a random-intercept-only model, ${ }^{2}$ with a singletrial-level (Level 1) predictor, homework-choice condition, for each of our eight post-manipulation outcome variables. HLM estimated classroom-level, student-level, and trial-level effects simultaneously. Thus, each level's effects are statistically independent of the others. As condition was a dichotomous (nohomework-choice $=0$ and homework-choice $=1$ ) predictor variable, there was no need to center. This basic model was run independently for each of our eight different outcomes.

Manipulation check. To assess whether the homework choice manipulation had affected students' post-manipulation perceptions of having received choice, we performed the basic model described above for perceived choice reported at the end of each unit. Overall, we found a significant main effect at the trial level for homework choice condition $\left(\hat{\gamma}_{100}=0.31, p<.0002\right)$. That is, students reported having greater choice regarding their homework while in the homework-choice condition compared with the nohomework-choice condition. These results provide support for the success of the manipulations. The results of this hierarchical linear model are summarized in Table 5.

The total variance at Level $1\left(\sigma^{2}\right)$ for post-manipulation perceived choice in the unconditional model was 0.64 . The error

\footnotetext{
${ }^{1}$ In the methodological literature, multiple imputation of missing data (Rubin, 1987) has often been recommended as an effective option for dealing with missing data (Schafer \& Graham, 2002). However, in light of the pattern of missing data that suggested that lower achieving students were less likely to complete measures associated with the study, it seemed unreasonable to impute missing values on the basis of the data provided by higher achieving students. Further, it seemed likely that the conditions necessary for multiple imputation to have desirable properties were not met. In particular, there was strong reason to suspect that the pattern of missing data was not missing at random, that is, the probability of missing data on a particular variable may depend on other observed variables but not on itself. For example, compared with students who were not missing a unit test score, students missing either test score in those from Unit 1 or 2 reported lower overall GPAs, $t(176)=2.15, p=.03$, had lower homework completion rates for Unit $1, t(17.1)=2.12, p=.05$, and Unit $2, t(18.6)=3.77, p=.001$, and lower homework grade averages in Unit $2, t(155)=5.20, p<.0001$. In short, at least for measures of achievement, the requirements for missing at random seem to have been violated, as missing a test was associated with lower scores on other measures of achievement

${ }^{2}$ A random intercept-only model was the most complex analysis the structure of this data could handle. Whereas a model that also included random slopes would have been interesting to explore, this was not possible because three time points would be needed in order to estimate the random slopes. This is because the inclusion of the random slope (as well as the random intercept) in the model allows each individual to have his or her own regression line. Because this data set included only two time points for each individual, each person's regression line fit his or her observed data perfectly, in which case we could not separate the true effect of slope differences from actual error.
} 
Table 1

Analysis 1 Fully Unconditional Models for Post-Manipulation Perceived Choice, Intrinsic Motivation, and Perceived Competence

\begin{tabular}{|c|c|c|c|c|c|c|c|c|c|}
\hline \multirow[b]{2}{*}{ Variable } & \multicolumn{3}{|c|}{$\begin{array}{l}\text { Post-manipulation perceived } \\
\text { choice }\end{array}$} & \multicolumn{3}{|c|}{$\begin{array}{l}\text { Post-manipulation intrinsic } \\
\text { motivation }\end{array}$} & \multicolumn{3}{|c|}{$\begin{array}{l}\text { Post-manipulation perceived } \\
\text { competence }\end{array}$} \\
\hline & Coefficient & $S E$ & $t(d f)$ & Coefficient & $S E$ & $t(d f)$ & Coefficient & $S E$ & $t(d f)$ \\
\hline \multicolumn{10}{|l|}{ Fixed effect } \\
\hline \multirow[t]{2}{*}{ Intercept $\left(\gamma_{000}\right)$} & $3.65^{* * *}$ & 0.11 & $34.28(13)$ & $3.37^{* * * *}$ & 0.09 & $35.55(13)$ & $4.86^{* * *}$ & 0.14 & $33.97(13)$ \\
\hline & $\begin{array}{l}\text { Variance } \\
\text { component }\end{array}$ & $S E$ & $Z$ & $\begin{array}{l}\text { Variance } \\
\text { component }\end{array}$ & $S E$ & $Z$ & $\begin{array}{l}\text { Variance } \\
\text { component }\end{array}$ & $S E$ & $Z$ \\
\hline \multicolumn{10}{|l|}{ Random effect } \\
\hline Class (Level $\left.3, \tau_{00}^{3}\right)$ & 0.05 & 0.06 & 0.81 & 0.04 & 0.05 & 0.85 & $0.20^{*}$ & 0.12 & 1.72 \\
\hline Student (Level 2, $\tau_{00}^{2}$ ) & $1.15^{* * * *}$ & 0.16 & 7.15 & $0.86^{\text {****** }}$ & 0.12 & 6.94 & $0.74^{\text {******* }}$ & 0.12 & 6.04 \\
\hline \multirow[t]{2}{*}{ Trial (Level $\left.1, \sigma^{2}\right)$} & $0.64^{* * *}$ & 0.07 & 9.05 & $0.51^{* * * *}$ & 0.06 & 9.00 & $0.66^{* * * *}$ & 0.07 & 9.04 \\
\hline & $\%$ by level & & & $\%$ by level & & & $\%$ by level & & \\
\hline \multicolumn{10}{|l|}{ Variance decomposition } \\
\hline Class (Level 3) & 2.72 & & & 2.84 & & & 12.50 & & \\
\hline Student (Level 2) & 62.50 & & & 60.99 & & & 46.25 & & \\
\hline Trial (Level 1) & 34.78 & & & 36.17 & & & 41.25 & & \\
\hline
\end{tabular}

${ }^{\dagger} p<.10 . \quad{ }^{*} p<.05 .{ }^{* * * *} p<.001$.

variance unaccounted for by the conditional Model 1 was reduced to 0.60 . Comparison of these results indicates that $6.3 \%$ of the variance in post-manipulation perceived choice could be explained on the basis of the homework choice manipulation.

Hypothesis testing. Next, to test the hypotheses that having choices regarding homework would result in greater postmanipulation interest and enjoyment (or self-reported intrinsic motivation), perceived competence, effort, value, and reduced feelings of pressure and tension regarding the homework, as well as more frequent homework completion and higher unit test scores, we ran seven hierarchical linear models using the basic model described previously, with homework-choice condition used to predict each of the post-manipulation outcome variables. The estimates from each model are summarized in Tables 5, 6, and 7. The observed pattern of results was consistent across many of the outcomes. Homework-choice condition was a significant predictor of post-manipulation interest and enjoyment (selfreported intrinsic motivation), perceived competence, unit test scores, and a marginally significant predictor of homework completion. This suggests that when students experienced a choice of homework assignments, they reported more enjoyment and interest in homework, feeling more competence for homework, completed more homework, and scored better on their unit tests compared with when they were not given a choice of homework. Homework-choice condition did not significantly predict the amount of effort students' reported putting forth on homework, their value for homework, or the pressure or tension felt during homework.

The total variance at Level 1 estimated in the unconditional model for the four significant or marginally significant outcomes

Table 2

Analysis 1 Fully Unconditional Models for Homework Completion Rate and Unit Test Score

\begin{tabular}{|c|c|c|c|c|c|c|}
\hline \multirow[b]{2}{*}{ Variable } & \multicolumn{3}{|c|}{ Homework completion rate } & \multicolumn{3}{|c|}{ Unit test score } \\
\hline & Coefficient & $S E$ & $t(d f)$ & Coefficient & $S E$ & $t(d f)$ \\
\hline \multicolumn{7}{|l|}{ Fixed effect } \\
\hline \multirow[t]{2}{*}{ Intercept $\left(\gamma_{000}\right)$} & $83.27^{* * * *}$ & 2.55 & $32.63(13)$ & $79.22^{* * *}$ & 0.94 & $84.44(13)$ \\
\hline & $\begin{array}{c}\text { Variance } \\
\text { component }\end{array}$ & $S E$ & $Z$ & $\begin{array}{c}\text { Variance } \\
\text { component }\end{array}$ & $S E$ & $Z$ \\
\hline \multicolumn{7}{|l|}{ Random effect } \\
\hline Class (Level $3, \tau_{00}^{3}$ ) & $46.65^{\dagger}$ & 34.94 & 1.33 & 1.44 & 4.83 & 0.30 \\
\hline Student (Level 2, $\left.\tau_{00}^{2}\right)$ & $257.11^{* * * *}$ & 73.78 & 3.48 & $81.77^{* * * *}$ & 18.47 & 4.43 \\
\hline \multirow[t]{2}{*}{ Trial $\left(\right.$ Level $\left.1, \sigma^{2}\right)$} & $721.62^{* * *}$ & 72.11 & 10.01 & $140.74^{* * * *}$ & 15.00 & 9.38 \\
\hline & $\%$ by level & & & \% by level & & \\
\hline \multicolumn{7}{|l|}{ Variance decomposition } \\
\hline Class (Level 3) & 4.55 & & & 0.64 & & \\
\hline Student (Level 2) & 25.07 & & & 36.51 & & \\
\hline Trial (Level 1) & 70.38 & & & 62.85 & & \\
\hline
\end{tabular}

${ }^{\dagger} p<.10 . \quad{ }^{* * * *} p<.001$. 
Table 3

Analysis 1 Fully Unconditional Models for Post-Manipulation Effort, Value, and Pressure/Tension

\begin{tabular}{|c|c|c|c|c|c|c|c|c|c|}
\hline \multirow[b]{2}{*}{ Variable } & \multicolumn{3}{|c|}{ Post-manipulation effort } & \multicolumn{3}{|c|}{ Post-manipulation value } & \multicolumn{3}{|c|}{ Post-manipulation pressure/tension } \\
\hline & Coefficient & $S E$ & $t(d f)$ & Coefficient & $S E$ & $t(d f)$ & Coefficient & $S E$ & $t(d f)$ \\
\hline \multicolumn{10}{|l|}{ Fixed effect } \\
\hline \multirow[t]{2}{*}{ Intercept $\left(\gamma_{000}\right)$} & $4.64^{* * * * *}$ & 0.09 & $49.53(13)$ & $4.71^{* * * *}$ & 0.14 & $33.40(13)$ & $2.71^{* * * * *}$ & 0.12 & $22.76(13)$ \\
\hline & $\begin{array}{l}\text { Variance } \\
\text { component }\end{array}$ & $S E$ & $Z$ & $\begin{array}{l}\text { Variance } \\
\text { component }\end{array}$ & $S E$ & $Z$ & $\begin{array}{l}\text { Variance } \\
\text { component }\end{array}$ & $S E$ & $Z$ \\
\hline \multicolumn{10}{|l|}{ Random effect } \\
\hline Class (Level 3, $\left.\tau_{00}^{3}\right)$ & 0.04 & 0.05 & 0.88 & $0.17^{\dagger}$ & 0.12 & 1.42 & $0.13^{\dagger}$ & 0.08 & 1.64 \\
\hline Student (Level 2, $\tau_{00}^{2}$ ) & $0.70^{* * * *}$ & 0.12 & 5.93 & $1.19^{* * * *}$ & 0.16 & 7.33 & $0.55^{\text {**** }}$ & 0.10 & 5.67 \\
\hline \multirow[t]{2}{*}{ Trial $\left(\right.$ Level $\left.1, \sigma^{2}\right)$} & $0.70^{* * * *}$ & 0.08 & 9.23 & $0.60^{* * * *}$ & 0.07 & 9.09 & $0.60^{\text {**** }}$ & 0.06 & 9.16 \\
\hline & $\%$ by level & & & $\%$ by level & & & $\%$ by level & & \\
\hline \multicolumn{10}{|l|}{ Variance decomposition } \\
\hline Class (Level 3) & 2.78 & & & 8.67 & & & 10.16 & & \\
\hline Student (Level 2) & 48.61 & & & 60.72 & & & 42.97 & & \\
\hline Trial (Level 1) & 48.61 & & & 30.61 & & & 46.87 & & \\
\hline
\end{tabular}

${ }^{\dagger} p<.10 .{ }^{* * * *} p<.001$.

were as follows: for post-manipulation interest/enjoyment, 0.51 ; for post-manipulation perceived competence, 0.66 ; for homeworkcompletion rate, 721.62; and for unit test score, 140.74. The error variance unaccounted for by homework choice manipulation in interest and enjoyment was reduced to 0.49 ; thus, homework choice condition accounted for $4.3 \%$ of the variance. The error variance unaccounted for in perceived competence was reduced to 0.65 ; thus, the model accounted for $2.2 \%$ of the variance. The error variance unaccounted for in homework completion was reduced to 714.44; thus, the model accounted for $1 \%$ of the variance. The error variance unaccounted for in unit test score was reduced to 138.92 ; thus, the model accounted for $1.3 \%$ of the variance.

\section{Analysis 2: The Role of Perceived Choice in the Context of Other Autonomy-Supportive Practices}

In Analysis 2, we tested the hypothesis that students' perceptions of being provided with choices will simultaneously support perceptions of receiving other forms of autonomy support. Consequently, perceived provision of choice will fully account for any relationship between motivation and students' perceptions of receiving other forms of autonomy support from their teachers. To test the prediction that perceived provision of choice would subsume the effects of perceiving other forms of autonomy support, we used analytic procedures traditionally used to assess mediation. Specifically, we per-

Table 4

Means (and Standard Deviations) for All Post-Manipulation Outcome Variables Used in Analysis 1 by Condition and Instructional Unit

\begin{tabular}{|c|c|c|c|c|c|c|}
\hline \multirow[b]{3}{*}{ Dependent variable } & \multicolumn{2}{|c|}{ Unit 1} & \multicolumn{2}{|c|}{ Unit 2} & \multicolumn{2}{|c|}{ Across units } \\
\hline & Choice & No choice & Choice & No choice & Choice & No choice \\
\hline & $M(S D)$ & $M(S D)$ & $M(S D)$ & $M(S D)$ & $M(S D)$ & $M(S D)$ \\
\hline Post-manipulation variable & $(n=89)$ & $(n=98)$ & $(n=90)$ & $(n=88)$ & $(n=179)$ & $(n=186)$ \\
\hline Perceived choice & $3.85(1.41)$ & $3.40(1.25)$ & $3.72(1.35)$ & $3.51(1.39)$ & $3.78(1.38)$ & $3.45(1.32)$ \\
\hline Interest/enjoyment & $3.49(1.12)$ & $3.25(1.13)$ & $3.41(1.33)$ & $3.25(1.13)$ & $3.45(1.23)$ & $3.25(1.13)$ \\
\hline Perceived competence & $5.05(1.23)$ & $4.89(1.20)$ & $4.97(1.33)$ & $4.74(1.24)$ & $5.01(1.28)$ & $4.82(1.22)$ \\
\hline Effort & $4.88(1.13)$ & $4.64(1.12)$ & $4.43(1.29)$ & $4.54(1.25)$ & $4.65(1.23)$ & $4.59(1.18)$ \\
\hline Value & $4.77(1.49)$ & $4.64(1.43)$ & $4.60(1.53)$ & $4.73(1.23)$ & $4.69(1.46)$ & $4.69(1.34)$ \\
\hline Pressure/tension & $2.55(1.19)$ & $2.57(1.01)$ & $2.85(1.17)$ & $2.75(1.11)$ & $2.70(1.19)$ & $2.66(1.34)$ \\
\hline \multirow[t]{2}{*}{ Homework completion rate } & $(n=98)$ & $(n=105)$ & $(n=105)$ & $(n=99)$ & $(n=203)$ & $(n=204)$ \\
\hline & $87.09(30.47)$ & $86.38(26.80)$ & $83.81(30.42)$ & $74.24(35.26)$ & $85.39(30.42)$ & $80.49(33.33)$ \\
\hline \multirow[t]{2}{*}{ Unit test score } & $(n=95)$ & $(n=100)$ & $(n=101)$ & $(n=93)$ & $(n=196)$ & $(n=193)$ \\
\hline & $77.95(12.65)$ & $76.11(16.09)$ & 83.49 (11.69) & $80.01(17.65)$ & $80.80(12.45)$ & 77.99 (16.93) \\
\hline
\end{tabular}

Note. This study utilized a repeated measures design such that participants in the Unit 1 homework-choice condition are the same participants who participated in the Unit 2 no-homework-choice condition. Likewise, participants in the Unit 2 homework-choice condition are the same participants who participated in the Unit 1 no-homework-choice condition. Finally, in the across-units columns, the same participants participated in the homework-choice and no-homework-choice conditions. The unequal $n$ s across cells with corresponding participants result from missing data for participants on select trials. 
Table 5

Analysis 1 Conditional Models for Post-Manipulation Perceived Choice, Intrinsic Motivation, and Perceived Competence

\begin{tabular}{|c|c|c|c|c|c|c|c|c|c|}
\hline \multirow[b]{2}{*}{ Variable } & \multicolumn{3}{|c|}{$\begin{array}{l}\text { Post-manipulation perceived } \\
\text { choice }\end{array}$} & \multicolumn{3}{|c|}{$\begin{array}{l}\text { Post-manipulation intrinsic } \\
\text { motivation }\end{array}$} & \multicolumn{3}{|c|}{$\begin{array}{l}\text { Post-manipulation perceived } \\
\text { competence }\end{array}$} \\
\hline & Coefficient & $S E$ & $t(d f)$ & Coefficient & $S E$ & $t(d f)$ & Coefficient & $S E$ & $t(d f)$ \\
\hline \multicolumn{10}{|l|}{ Fixed effect } \\
\hline Intercept $\left(\gamma_{000}\right)$ & $3.49^{* * * *}$ & 0.11 & $30.75(13)$ & $3.27^{* * * *}$ & 0.10 & $32.09(13)$ & $4.77^{* * * *}$ & 0.15 & $32.05(13)$ \\
\hline \multirow[t]{2}{*}{ Condition $^{\mathrm{a}}\left(\gamma_{100}\right)$} & $0.31^{\text {***** }}$ & 0.08 & $3.72(350)$ & $0.22^{* *}$ & 0.08 & $2.83(350)$ & $0.19^{*}$ & 0.09 & $2.16(350)$ \\
\hline & $\begin{array}{c}\text { Variance } \\
\text { component }\end{array}$ & $S E$ & $Z$ & $\begin{array}{l}\text { Variance } \\
\text { component }\end{array}$ & $S E$ & $Z$ & $\begin{array}{l}\text { Variance } \\
\text { component }\end{array}$ & $S E$ & $Z$ \\
\hline \multicolumn{10}{|l|}{ Random effect } \\
\hline Class (Level 3, $\tau_{00}^{3}$ ) & 0.05 & 0.06 & 0.81 & 0.04 & 0.05 & 0.86 & $0.20^{*}$ & 0.12 & 1.72 \\
\hline Student (Level 2, $\tau_{00}^{2}$ ) & $1.17^{* * * *}$ & 0.16 & 7.31 & $0.87^{* * * *}$ & 0.12 & 7.06 & $0.75^{* * *}$ & 0.12 & 6.11 \\
\hline Trial (Level $\left.1, \sigma^{2}\right)$ & $0.60^{\text {******* }}$ & 0.07 & 9.03 & $0.49^{\text {***** }}$ & 0.05 & 8.97 & $0.65^{* * *}$ & 0.07 & 9.01 \\
\hline
\end{tabular}

${ }^{\mathrm{a}} 0=$ no-homework choice; $1=$ homework choice.

${ }^{*} p<.05$. $^{* *} p<.01$. $^{* * *} p<.001$.

formed a series of analyses to evaluate the direct, indirect, and total effects of perceived autonomy support on motivation and achievement through perceived provision of choice in the context of a multilevel model using mediation procedures suggested by Bauer, Preacher, and Gil (2006). Again, we used HLM for our primary tests in Analysis 2 because it appropriately addressed the hierarchically nested design of our data set, in which lower level units, students, were nested within a higher level unit, classes.

The multilevel mediation procedures suggested by Bauer et al. (2006) may be considered an application to the multilevel context of well-known mediation procedures used in the regression context, as suggested by Baron and Kenny (1986). Multilevel mediation analyses are conducted similarly to single-level mediation by fitting a sequence of models. Further, like single-level mediation analysis, several criteria must be met: (a) there must be a significant relation between the independent and dependent variable, (b) there must be a significant relation between the independent and mediating variables, (c) there must be a significant relation between the mediating and dependent variables, and (d) the relation of the independent variable to the dependent variable must decrease when the mediating variable is included in the model.
However, unlike single-level mediation analysis, within- and between-group effects need to be decomposed in multilevel mediation in which all predictors and mediators are measured at Level 1.

Several outcome variables were of interest in Analysis 2. In addition to testing whether the perceived provision of choice could account for the relationship between perceived autonomy support at school and intrinsic motivation for schoolwork, we also examined whether perceived provision of choice accounted for any relationship that might exist between perceived autonomy support and identified regulation for schoolwork, as well as overall GPA.

For Analysis 2, we used information students provided in the background and school experiences questionnaire collected prior to manipulating choices of homework described in Analysis 1. All of the baseline measures used in Analysis 2 assessed students' perceptions of school in general, rather than in the particular class in which the questionnaires were administered. We chose to assess students' perceptions at baseline for the learning environment in general, rather than for a specific class, for two reasons. First, this kept the hypotheses addressed regarding the homework choice manipulation clearly distinguished from the hypotheses addressing the role of perceptions of provision of choice in Analysis 2.

Table 6

Analysis 1 Conditional Models for Homework Completion Rate and Unit Test Score

\begin{tabular}{|c|c|c|c|c|c|c|}
\hline \multirow[b]{2}{*}{ Variable } & \multicolumn{3}{|c|}{ Homework completion rate } & \multicolumn{3}{|c|}{ Unit test score } \\
\hline & Coefficient & $S E$ & $t(d f)$ & Coefficient & $S E$ & $t(d f)$ \\
\hline \multicolumn{7}{|l|}{ Fixed effect } \\
\hline Intercept $\left(\gamma_{000}\right)$ & $80.88^{* * * *}$ & 2.87 & $28.15(13)$ & $77.93^{* * * *}$ & 1.12 & $69.71(13)$ \\
\hline \multirow[t]{2}{*}{ Condition $^{\mathrm{a}}\left(\gamma_{100}\right)$} & $4.80^{\dagger}$ & 2.65 & $1.81(392)$ & $2.56^{*}$ & 1.21 & $2.12(374)$ \\
\hline & $\begin{array}{l}\text { Variance } \\
\text { component }\end{array}$ & $S E$ & $Z$ & $\begin{array}{l}\text { Variance } \\
\text { component }\end{array}$ & $S E$ & $Z$ \\
\hline \multicolumn{7}{|l|}{ Random effect } \\
\hline Class (Level $3, \tau_{00}^{3}$ ) & $46.66^{\dagger}$ & 34.93 & 1.34 & 1.49 & 4.83 & 0.31 \\
\hline Student (Level 2, $\tau_{00}^{2}$ ) & $259.97^{* * * *}$ & 73.53 & 3.54 & $81.86^{* * * *}$ & 18.31 & 4.47 \\
\hline Trial (Level $\left.1, \sigma^{2}\right)$ & $714.44^{* * * *}$ & 71.54 & 9.99 & $138.92^{* * * *}$ & 14.82 & 9.37 \\
\hline
\end{tabular}

${ }^{\text {a }} 0=$ no-homework choice; $1=$ homework choice

${ }^{\dagger} p<.10 .{ }^{*} p<.05$. **** $p<.001$. 
Table 7

Analysis 1 Conditional Models for Post-Manipulation Effort, Value, and Pressure/Tension

\begin{tabular}{|c|c|c|c|c|c|c|c|c|c|}
\hline \multirow[b]{2}{*}{ Variable } & \multicolumn{3}{|c|}{ Post-manipulation effort } & \multicolumn{3}{|c|}{ Post-manipulation value } & \multicolumn{3}{|c|}{ Post-manipulation pressure/tension } \\
\hline & Coefficient & $S E$ & $t(d f)$ & Coefficient & $S E$ & $t(d f)$ & Coefficient & $S E$ & $t(d f)$ \\
\hline \multicolumn{10}{|l|}{ Fixed effect } \\
\hline Intercept $\left(\gamma_{0 o 0}\right)$ & $4.60^{* * *}$ & 0.10 & $44.44(13)$ & $4.70^{* * *}$ & 0.15 & $32.00(13)$ & $2.69^{* * *}$ & 0.13 & $21.32(13)$ \\
\hline \multirow[t]{2}{*}{ Condition $^{\mathrm{a}}\left(\gamma_{100}\right)$} & 0.08 & 0.09 & $0.83(350)$ & 0.02 & 0.08 & $0.28(350)$ & 0.05 & 0.08 & $0.66(350)$ \\
\hline & $\begin{array}{c}\text { Variance } \\
\text { component }\end{array}$ & $S E$ & $Z$ & $\begin{array}{c}\text { Variance } \\
\text { component }\end{array}$ & $S E$ & $Z$ & $\begin{array}{c}\text { Variance } \\
\text { component }\end{array}$ & $S E$ & $Z$ \\
\hline \multicolumn{10}{|l|}{ Random effect } \\
\hline Class (Level 3, $\tau_{00}^{3}$ ) & 0.04 & 0.05 & 0.89 & $0.17^{\dagger}$ & 0.12 & 1.42 & $0.13^{\dagger}$ & 0.08 & 1.64 \\
\hline Student (Level 2, $\tau_{00}^{2}$ ) & $0.70^{* * * *}$ & 0.12 & 5.93 & $1.19^{* * *}$ & 0.16 & 7.32 & $0.55^{\text {**** }}$ & 0.10 & 5.65 \\
\hline Trial (Level $\left.1, \sigma^{2}\right)$ & $0.70^{* * * *}$ & 0.08 & 9.20 & $0.60^{* * * *}$ & 0.07 & 9.06 & $0.60^{* * * *}$ & 0.07 & 9.13 \\
\hline
\end{tabular}

a $0=$ no-homework choice; $1=$ homework choice

${ }^{\dagger} p<.10 .{ }^{* * * *} p<.001$.

Second, we intended to use overall GPA as an outcome measure in Analysis 2. Because GPA is a general assessment of achievement across all classes, we wanted to assess all variables used to predict GPA at this same general level. The means, standard deviations, and intercorrelations for all variables used in Analysis 2 can be found in Table 8 .

First, we calculated ICCs for all relevant outcome variables from their unconditional models. The ICCs suggested that an HLM approach would provide an advantage over a standard fixed-effects model approach, at least for some outcome variables (baseline perceived provision of choice: $I C C=.01$; baseline intrinsic motivation for schoolwork: $I C C=.06$; baseline identified regulation for schoolwork: $I C C=.005$; GPA: $I C C=.10)$. The variance component for class $\left(\tau_{00}\right)$ was not significant in the unconditional model for any variable. Nevertheless, we decided to retain this term in the model because inclusion of this term was consistent with the data structure, the lack of significance may have been a reflection of lower power at Level 2, and the two-level structure did not produce any estimation difficulties. The results of these unconditional hierarchical linear models are summarized in Table 9.

Next, to test our hypotheses, we conducted a series of models. In the first model, we ran a random-intercept-only model that included two covariates that we wanted to control for when predicting the dependent variables, ethnicity (White $=1$, non-
White $=0)$ and sex $($ male $=0$, female $=1)$, as well as the main Level 1 predictors, baseline perceived autonomy support and baseline perceived competence. All covariates and predictors were class-mean-centered to obtain the within-class total effect estimate. In addition, class means for the covariates and predictors were also entered into the model to obtain the betweenclass total effect estimate for each. In the second model, we regressed baseline perceived provision of choice on the same set of predictors as in the previous model using a randomintercept-only model to obtain the first part of the within-class and between-class indirect effect estimates. In the final model, we entered the full model (class mean centered and class means for covariates, baseline perceived autonomy support, baseline perceived competence, baseline perceived provision of choice) to predict the outcome variable and obtain the within-class direct effect estimate, and the second part of the within-class indirect effect estimate, as well as the corresponding betweenclass direct and indirect effect estimates.

This set of models was run independently for intrinsic motivation for schoolwork and overall GPA. A similar set of models that included only the class-mean-centered predictors and covariates and excluded the class means for predictors and covariates was run independently for identified regulation for schoolwork. This alternate model was run for identified regu-

Table 8

Means, Standard Deviations, and Intercorrelations Among Baseline Variables Used in Analysis 2

\begin{tabular}{|c|c|c|c|c|c|c|c|c|c|}
\hline Measure & $M(S D)$ & 1 & 2 & 3 & 4 & 5 & 6 & 7 & 8 \\
\hline 1. Baseline perceived provision of choice & $3.06(0.94)$ & - & & & & & & & \\
\hline 2. Baseline perceived autonomy support & $4.62(1.12)$ & $.43^{\text {****** }}$ & - & & & & & & \\
\hline 3. Baseline perceived competence & $5.21(1.18)$ & $.34^{* * * * *}$ & $.57^{* * * *}$ & - & & & & & \\
\hline 4. Baseline intrinsic motivation & $2.87(1.22)$ & $.31^{\text {**** }}$ & $.26^{* * * *}$ & $.25^{\text {***** }}$ & - & & & & \\
\hline 5. Baseline identified regulation & $4.84(1.17)$ & $.25^{* * * *}$ & $.42^{* * * *}$ & $.46^{* * * *}$ & $.52^{* * * *}$ & - & & & \\
\hline 6. GPA & $3.34(0.71)$ & .08 & $.26^{* * * *}$ & $.34^{* * * *}$ & .04 & $.15^{*}$ & - & & \\
\hline 7. Ethnicity ${ }^{\mathrm{a}}$ & $0.59(0.49)$ & .01 & .05 & $.13^{\dagger}$ & -.12 & -.11 & $.30^{* * * * *}$ & - & \\
\hline 8. Sex ${ }^{\mathrm{b}}$ & $0.54(0.50)$ & -.04 & -.01 & -.06 & .01 & .11 & $.28^{* * * *}$ & -.05 & - \\
\hline
\end{tabular}

Note. $\quad N=200$.

${ }^{\mathrm{a}}$ Ethnicity: White $=1$, non-White $=0 .{ }^{\mathrm{b}}$ Sex: $0=$ male, $1=$ female

${ }^{\dagger} p<.10 .{ }^{*} p<.05 .{ }^{* * * *} p<.001$. 


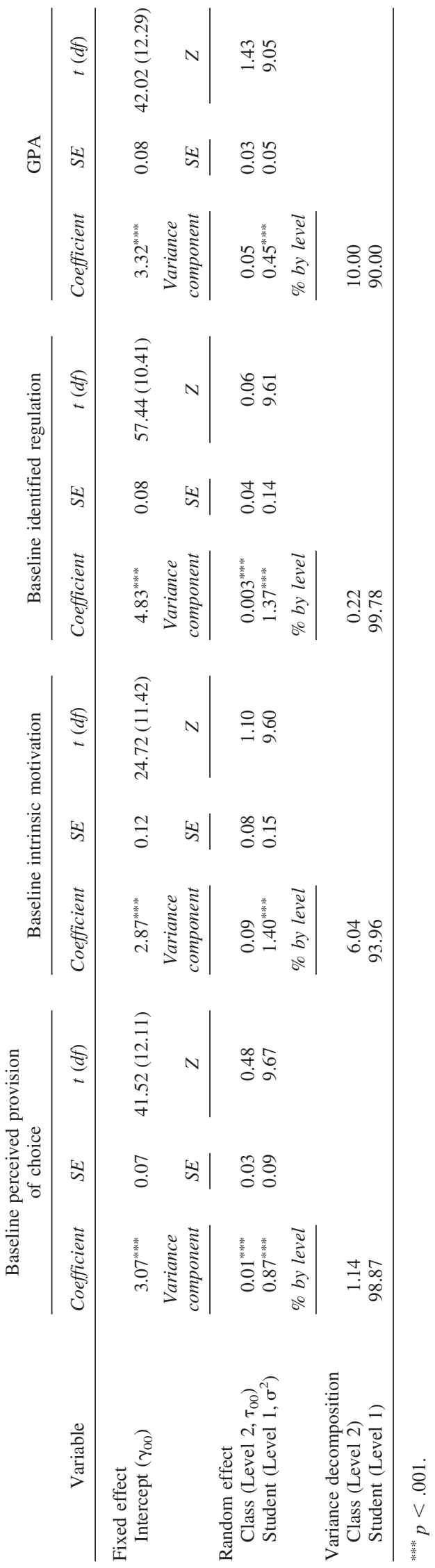

lation due to the near zero variance attributable to class and evidence suggesting that the validity of models including class means was questionable for this outcome. As such, results only address within-class effects for this particular outcome. Further, in an effort to assess a more complete model of motivation compared with one that only included supports for autonomy, baseline perceived competence was included in these models. Baseline perceived competence was included because, in addition to the need for autonomy, the need for competence is hypothesized to underlie intrinsic motivation according to selfdetermination theory. As such, perceived competence was expected to predict variability in motivation and achievement, in addition to that accounted for by perceived autonomy support and perceived provision of choice.

Intrinsic motivation for schoolwork. Sex and ethnicity did not significantly predict baseline intrinsic motivation for schoolwork either within or between classes. However, controlling for the covariates, there was a significant fixed effect of baseline perceived autonomy support within classes, but not between classes, indicating that within any given class, students with higher levels of perceived autonomy support reported greater intrinsic motivation for schoolwork. There was a marginally significant effect of baseline perceived competence within classes, but not between classes.

As expected, controlling for the covariates and baseline perceived competence, there was a significant relationship between baseline perceived autonomy support and baseline perceived provision of choice both within and between classes, indicating that higher perception of receiving autonomy-support both within and between classes was related to higher perceptions of having choices. No other variables in the model predicted perceived provision of choice.

Finally, the full model predicting baseline intrinsic motivation for schoolwork was estimated. As shown in Table 10, the coefficient for the relationship between baseline perceived autonomy support and baseline intrinsic motivation was initially 0.20 ( $p=$ $.04)$ within classes. That value dropped to $0.11(p=.28)$ when baseline perceived provision of choice at school was added to the model. The Sobel test (Sobel, 1982) confirmed that within any given class, baseline perceived provision of choice was a significant mediator of the relation between baseline perceived autonomy support and baseline intrinsic motivation for schoolwork $(z=$ 2.50, $p<.01$ ). There was little change in other variables as a function of adding perceived provision of choice to the model. As expected, even when controlling for covariates, perceived autonomy support, and perceived competence, the perception of having choices significantly predicted intrinsic motivation for schoolwork within classes, all measured at baseline. Results suggest that perceptions of being given choices at school may indeed simultaneously support the perception of receiving other forms of autonomy support from teachers.

The total variance at Level $1\left(\sigma^{2}\right)$ for baseline intrinsic motivation in the unconditional model was 1.40 . The error variance unaccounted for by the conditional model without baseline-perceived provision of choice was reduced to 1.32 . Comparison of these results indicates that $5.7 \%$ of the variance in baseline intrinsic motivation for schoolwork was explained The error variance was further reduced to 1.26 in the conditional model that included baseline perceived provision of 
Table 10

Analysis 2 Conditional Models for Baseline Perceived Provision of Choice and Baseline Intrinsic Motivation

\begin{tabular}{|c|c|c|c|c|c|c|c|c|c|}
\hline \multirow[b]{2}{*}{ Variable } & \multicolumn{3}{|c|}{ Baseline perceived provision of choice } & \multicolumn{3}{|c|}{ Baseline intrinsic motivation } & \multicolumn{3}{|c|}{ Baseline intrinsic motivation } \\
\hline & Coefficient & $S E$ & $t(d f)$ & Coefficient & $S E$ & $t(d f)$ & Coefficient & $S E$ & $t(d f)$ \\
\hline \multicolumn{10}{|l|}{ Fixed effect } \\
\hline Intercept $\left(\gamma_{00}\right)$ & 3.09 & 1.42 & $2.18(8.29)$ & 2.93 & 2.19 & $1.34(9.16)$ & $1.42^{* * * *}$ & 2.64 & $0.54(7.46)$ \\
\hline Ethnicity $^{\mathrm{a}}\left(\gamma_{10}\right)$ & 0.03 & 0.14 & $0.24(170.99)$ & -0.25 & 0.18 & $-1.34(170.76)$ & -0.25 & 0.18 & $-1.43(169.09)$ \\
\hline $\operatorname{Sex}^{\mathrm{b}}\left(\gamma_{20}\right)$ & -0.06 & 0.13 & $-0.48(171.82)$ & 0.07 & 0.18 & $0.42(171.50)$ & 0.09 & 0.17 & $0.54(169.82)$ \\
\hline Baseline perceived autonomy support $\left(\gamma_{30}\right)$ & $0.31^{* * * *}$ & 0.07 & $4.33(171.16)$ & $0.20^{*}$ & 0.10 & $2.11(170.86)$ & 0.11 & 0.10 & $1.09(169.26)$ \\
\hline Baseline perceived competence $\left(\gamma_{40}\right)$ & 0.04 & 0.07 & $0.56(171.55)$ & $0.15^{\dagger}$ & 0.09 & $1.67(171.16)$ & 0.14 & 0.09 & $1.58(169.47)$ \\
\hline Baseline perceived provision of choice $\left(\gamma_{50}\right)$ & & & & & & & $0.31^{* *}$ & 0.10 & $3.06(169.45)$ \\
\hline Mean ethnicity $\left(\gamma_{01}\right)$ & -0.18 & 0.49 & $-0.36(10.45)$ & -1.36 & 0.75 & $-1.80(10.42)$ & -1.28 & 0.76 & $-1.69(8.55)$ \\
\hline Mean $\operatorname{sex}^{\mathrm{b}}\left(\gamma_{02}\right)$ & -0.15 & 0.56 & $-0.27(8.54)$ & -1.16 & 0.87 & $-1.34(9.19)$ & -1.07 & 0.88 & $-1.23(7.38)$ \\
\hline Mean baseline perceived autonomy support $\left(\gamma_{03}\right)$ & $0.58^{*}$ & 0.24 & $2.45(8.57)$ & -0.08 & 0.37 & $-0.23(8.92)$ & -0.37 & 0.47 & $-0.80(7.70)$ \\
\hline Mean baseline perceived $\left(\gamma_{04}\right)$ & -0.49 & 0.29 & $-1.66(10.35)$ & 0.36 & 0.45 & $0.80(10.45)$ & 0.59 & 0.50 & $1.18(8.52)$ \\
\hline \multirow[t]{2}{*}{ Mean baseline perceived provision of choice $\left(\gamma_{05}\right)$} & & & & & & & 0.51 & 0.51 & $1.00(8.12)$ \\
\hline & $\begin{array}{l}\text { Variance } \\
\text { component }\end{array}$ & $S E$ & $Z$ & $\begin{array}{l}\text { Variance } \\
\text { component }\end{array}$ & $S E$ & $Z$ & $\begin{array}{l}\text { Variance } \\
\text { component }\end{array}$ & $S E$ & $Z$ \\
\hline \multicolumn{10}{|l|}{ Random effect } \\
\hline Class (Level 2, $\left.\tau_{00}\right)$ & 0.01 & 0.03 & 0.23 & 0.04 & 0.07 & 0.68 & 0.05 & 0.07 & 0.70 \\
\hline Student (Level $1, \sigma^{2}$ ) & $0.74^{* * * *}$ & 0.08 & 9.24 & $1.32^{* * * *}$ & 0.14 & 9.24 & $1.26^{* * * *}$ & 0.14 & 9.19 \\
\hline
\end{tabular}

${ }^{\mathrm{a}}$ Ethnicity: White $=1$, non-White $=0 .{ }^{\mathrm{b}}$ Sex: $0=$ male, $1=$ female

${ }^{\dagger} p<.10 . \quad * p<.05 .{ }^{* * *} p<.01{ }^{* * * *} p<.001$. 
choice. Comparison of these results with the conditional model without baseline-perceived provision of choice indicates that an additional $4.6 \%$ of the variance in baseline intrinsic motivation for schoolwork was explained with this addition of perceived provision of choice.

Identified regulation for schoolwork. A similar sequence of models was run for baseline identified regulation for schoolwork, or the intention to engage in schoolwork because it is personally valued or important. However, a different pattern of results emerged. Ethnicity significantly predicted baseline identified regulation for schoolwork within classes, with non-White students demonstrating greater identified regulation for schoolwork. In addition, there were significant fixed effects of baseline perceived autonomy support and baseline perceived competence within classes, indicating that students with higher levels of perceived autonomy support and perceived competence had greater identified regulation for schoolwork. However, as shown in Table 11, there was not a significant relation between baseline perceived provision of choice and identified regulation for schoolwork within classes.

The total variance at Level $1\left(\sigma^{2}\right)$ for baseline identified regulation in the unconditional model was 1.37. The error variance unaccounted for by the conditional model without baseline perceived provision of choice was reduced to 0.98. Comparison of these results indicates that $28.5 \%$ of the variance in baseline identified regulation for schoolwork was explained. The error variance was further reduced only to 0.97 in the conditional model that included perceived provision of choice, explaining an additional $1 \%$ of the variance in baseline intrinsic motivation for schoolwork compared with the previous conditional model.

Grade point average. Finally, we examined our hypotheses regarding the role of perceived provision of choice in the context of other forms of autonomy support with overall GPA as the outcome. Ethnicity and sex significantly predicted GPA within classes, indicating that women had significantly higher selfreported GPAs than men and that White students had significantly higher GPAs compared with non-White students. In addition, there were significant fixed effects of baseline perceived autonomy support and baseline perceived competence within classes, indicating that within any given class, higher levels of students' perceived autonomy support and perceived competence predicted higher GPA. Further, there was a significant effect of baseline perceived competence between classes. However, as with identified regulation, we found no significant relation between baseline perceived provision of choice and GPA either within or between classes (see Table 11).

The total variance at Level $1\left(\sigma^{2}\right)$ for GPA in the unconditional model was 0.45 . The error variance unaccounted for by the conditional model without baseline perceived provision of choice was reduced to 0.34 . Comparison of these results indicates that $24.5 \%$ of the variance in GPA for schoolwork was explained. The error variance was not further reduced in the conditional model that included baseline perceived provision of choice.

\section{Discussion}

The purpose of this investigation was (a) to test the utility of implementing choices in the classroom and (b) to examine the importance of students' perceptions of having choices relative to other teaching practices meant to support feelings of autonomy. Overall and in line with self-determination theory, results suggested that providing students with choices among homework tasks effectively enhanced motivational and performance outcomes and that choice is an important component to creating a classroom environment supportive of autonomy and intrinsic motivation.

\section{Manipulation of Homework Choices}

The experimental portion of this study examined whether providing students with choices of homework assignments would enhance motivation, perceived competence, and performance compared with having no homework choices. Consistent with self-determination theory, we found that students reported feeling more interested in and enjoying homework more as well as more competent regarding their homework and that they scored higher on the unit test when they received a choice between two homework assignments covering the same content and of intermediate difficulty, compared with when they were not given a choice. Students also tended to complete more of their homework when provided with choices. However, receiving choices of homework assignments seemed to have little effect on the amount of effort students put into doing the homework, the amount of pressure or tension they felt while doing the homework, or their value for the homework.

Unlike previous studies, this study experimentally manipulated the provision of choice in the context of real classrooms with real students and teachers. Choices were implemented by the teachers themselves and integrated into the everyday happenings of the class. Further, we focused on the provision of choice within a specific pedagogical strategy, homework, that research has demonstrated to be effective for enhancing academic achievement (Cooper, 1989; Cooper et al., 2006).

Clearly, there were benefits for the student of having a choice of homework assignments. However, anecdotally, it was also clear that these benefits were not gained without cost. That is, providing multiple homework options for every homework assignment placed an additional burden on the teachers who had to design, distribute, and collect these assignments. Consequently, in order to reduce the burden on teachers, an important initial step for schools and school districts trying to implement homework choices regularly in classrooms may be to develop a system by which teachers can share homework with others teaching the same course or at the same grade level. In particular, Internet databases where teachers can post homework by grade level, course, and topic may be useful for helping teachers implement homework choices. Similarly, efforts to organize textbooks such that multiple, alternative end-of-chapter questions and exercises are provided may be another effective way to facilitate the implementation of choices within the classroom. Finally, while we investigated the utility of choice within the specific pedagogical strategy of homework, we believe that the benefits of providing choices are likely to extend to other forms of schoolwork and other pedagogical strategies.

\section{The Role of Providing Choices in Autonomy-Supportive Classrooms}

As a second question, we examined the importance of students' perceptions of having choices relative to other autonomysupportive teaching practices. To do so, we applied a meditational 
Table 11

Analysis 2 Conditional Models for Baseline Identified Regulation and Grade Point Average (GPA)

\begin{tabular}{|c|c|c|c|c|c|c|c|c|c|c|c|c|}
\hline \multirow[b]{2}{*}{ Variable } & \multicolumn{3}{|c|}{$\begin{array}{l}\text { Baseline identified regulation } \\
\text { (without mediator) }\end{array}$} & \multicolumn{3}{|c|}{$\begin{array}{l}\text { Baseline identified regulation } \\
\text { (with mediator) }\end{array}$} & \multicolumn{3}{|c|}{ GPA (without mediator) } & \multicolumn{3}{|c|}{ GPA (with mediator) } \\
\hline & Coefficient & $S E$ & $t(d f)$ & Coefficient & $S E$ & $t(d f)$ & Coefficient & $S E$ & $t(d f)$ & Coefficient & $S E$ & $t(d f)$ \\
\hline \multicolumn{13}{|l|}{ Fixed effect } \\
\hline Intercept $\left(\gamma_{00}\right)$ & $4.93^{* * * *}$ & 0.15 & $33.14(64.46)$ & $4.93^{* * * *}$ & 0.15 & $33.19(63.64)$ & 0.87 & 1.26 & $0.70(8.72)$ & 0.93 & 1.61 & $0.58(7.55)$ \\
\hline Ethnicity $^{\mathrm{a}}\left(\gamma_{10}\right)$ & $-0.36^{*}$ & 0.15 & $-2.41(181.65)$ & $-0.37^{*}$ & 0.15 & $-2.44(180.72)$ & $0.32^{* *}$ & 0.10 & $3.17(152.99)$ & $0.32^{* *}$ & 0.10 & $3.16(151.51)$ \\
\hline $\operatorname{Sex}^{\mathrm{b}}\left(\gamma_{20}\right)$ & 0.23 & 0.15 & $1.53(180.91)$ & 0.23 & 0.15 & $1.60(179.78)$ & $0.44^{* * * *}$ & 0.09 & $4.73(152.15)$ & $0.44^{* * * *}$ & 0.09 & $4.72(150.74)$ \\
\hline Baseline perceived autonomy & & & & & & & & & & & & \\
\hline support $\left(\gamma_{30}\right)$ & $0.22^{* * *}$ & 0.08 & $2.64(169.12)$ & $0.18^{*}$ & 0.09 & $2.03(168.07)$ & $0.10^{*}$ & 0.05 & $2.04(152.16)$ & $0.10^{\dagger}$ & 0.05 & $1.91(150.52)$ \\
\hline Baseline perceived competence $\left(\gamma_{40}\right)$ & $0.37^{* * * *}$ & 0.08 & $4.72(169.55)$ & $0.36^{* * * *}$ & 0.08 & $4.67(168.39)$ & $0.10^{*}$ & 0.05 & $2.00(152.32)$ & $0.10^{\dagger}$ & 0.05 & $1.98(150.91)$ \\
\hline $\begin{array}{l}\text { Baseline perceived provision of } \\
\text { choice }\left(\gamma_{50}\right)\end{array}$ & & & & 0.14 & 0.09 & $1.53(168.50)$ & & & & 0.01 & 0.06 & $0.14(150.12)$ \\
\hline Mean ethnicity ${ }^{\mathrm{a}}\left(\gamma_{01}\right)$ & & & & & & & 0.19 & 0.44 & $0.43(10.09)$ & 0.20 & 0.46 & $0.43(8.63)$ \\
\hline Mean $\operatorname{sex}^{\mathrm{b}}\left(\gamma_{02}\right)$ & & & & & & & -0.29 & 0.50 & $-0.59(8.94)$ & -0.31 & 0.54 & $-0.58(7.56)$ \\
\hline Mean baseline perceived autonomy & & & & & & & & & & & & \\
\hline support $\left(\gamma_{03}\right)$ & & & & & & & -0.28 & 0.21 & $-1.32(8.42)$ & -0.28 & 0.28 & $-1.01(7.42)$ \\
\hline Mean BS perceived competence $\left(\gamma_{04}\right)$ & & & & & & & $0.65^{*}$ & 0.26 & $2.51(9.66)$ & $0.64^{\dagger}$ & 0.30 & $2.11(8.30)$ \\
\hline \multirow[t]{2}{*}{$\begin{array}{l}\text { Mean baseline perceived provision of } \\
\text { choice }\left(\gamma_{05}\right)\end{array}$} & & & & & & & & & & 0.00 & 0.31 & $0.01(7.67)$ \\
\hline & $\begin{array}{l}\text { Variance } \\
\text { component }\end{array}$ & $S E$ & $Z$ & $\begin{array}{l}\text { Variance } \\
\text { component }\end{array}$ & $S E$ & $Z$ & $\begin{array}{l}\text { Variance } \\
\text { component }\end{array}$ & $S E$ & $Z$ & $\begin{array}{l}\text { Variance } \\
\text { component }\end{array}$ & $S E$ & $Z$ \\
\hline \multicolumn{13}{|l|}{ Random effect } \\
\hline Class (Level 2, $\tau_{00}$ ) & 0.03 & 0.04 & 0.69 & 0.03 & 0.04 & 0.71 & 0.02 & 0.02 & 0.84 & 0.02 & 0.03 & 0.90 \\
\hline Student (Level $1, \sigma^{2}$ ) & $0.98^{* * * *}$ & 0.11 & 9.18 & $0.97^{* * * *}$ & 0.11 & 9.15 & $0.34^{* * * *}$ & 0.04 & 8.68 & $0.35^{* * * *}$ & 0.04 & 8.65 \\
\hline
\end{tabular}

${ }^{\mathrm{a}}$ Ethnicity: White $=1$, non-White $=0 .{ }^{\mathrm{b}}$ Sex: $0=$ male, $1=$ female.

${ }^{\dagger} p<.10 .{ }^{*} p<.05 .{ }^{* * *} p<.01 .{ }^{* * * *} p<.001$. 
analytic strategy to baseline student survey data of the degree to which they received choices from their teachers at school, their perceptions of teachers as engaging in autonomy-supportive behaviors, their feelings of competence for schoolwork, and their motivation and performance in school. Whereas the same students who participated in the homework choice manipulation participated in answering this question, the measures for this analysis were taken one to two weeks prior to the experimental manipulation of homework choices so that the effects of having choices of homework would not influence these survey responses. Consistent with self-determination theory, we found that student perceptions of receiving autonomy support from their teachers predicted intrinsic motivation for schoolwork. However, students' perceptions of receiving choices from teachers at school fully accounted for this relationship, suggesting that choice may simultaneously support the perception of receiving other forms of autonomy support.

This result highlights how useful providing choice can be to establishing a classroom environment and a teaching style that supports students' interest and enjoyment for school tasks. The measure of perceived autonomy support asked students the degree to which they felt that their teachers listen, understand, encourage, care about and accept them, allow and answer questions, provide rationales, and are trustworthy. Intentionally excluded from the measure of autonomy support were questions related to the degree of choice students' felt their teachers provided. Thus, results suggest that students will also feel that teachers are actually providing rationales, listening to them, understanding them, and encouraging or accepting them when they perceive that they have the opportunity for making choices. Providing choices may be the most concrete way for teachers to communicate to students that they view them as autonomous learners. Alternatively, not providing choice may convey the opposite message.

We also tested this model with identified regulation for schoolwork and GPA. Again, perceptions of receiving autonomy support from teachers predicted greater identified regulation for schoolwork and higher GPA, as did perceptions of competence for schoolwork. However, students' perceptions of receiving choices at school did not significantly predict either identified regulation or GPA. These results suggest that other autonomy-supportive practices may be more essential for supporting students' intention to engage in schoolwork because they value that work, as well as their general achievement at school. It is also worth noting that the lack of relationship found in Analysis 2 between perceived provision of choice at school and identified regulation for schoolwork was in line with the results of our experimental portion of the study, showing that whether or not students received a choice of homework had little impact on their value for homework. In part, these findings are fully consistent with self-determination theory. That is, autonomy support is proposed to support all forms of autonomous motivation (e.g., identified regulation) and outcomes that are subsequently influenced by autonomous motivation (e.g., GPA). However, according to self-determination theory, we might also have expected to find that perceptions of receiving choices would be just as useful in supporting identified regulation as they are for supporting intrinsic motivation. Rather, findings suggest that different autonomy-supportive practices may support different motivational and learning-related outcomes.
Findings of this study may appear at odds with some previous research. As mentioned earlier, several researchers have suggested that choice may not always be effective or that there are more effective strategies to support motivation (Assor et al., 2002; Reeve et al., 2003; Stefanou et al., 2004). For example, Reeve et al. (2003) suggested that choices that also support an internal locus of causality and volition will most effectively enhance intrinsic motivation. In particular, choices that involved making decisions regarding the actions one takes were found to be effective because they also enhanced perceptions of having an internal locus of causality and volition. However, choices made between experimenter-determined options of a task were postulated to have little impact on an internal locus or volition and consequently and were found to have little effect on intrinsic motivation. Likewise, as previously discussed, Katz and Assor (2007) suggested that choice may be more or less effective depending on the extent to which it satisfies fundamental needs for autonomy, competence, and relatedness. They suggested that choices that are relevant to students' interests and goals (autonomy supportive), provide a moderate number of options of an intermediate level of complexity (competence supportive), and are congruent with other family and cultural values (relatedness supportive) will be effective for supporting motivation and related outcomes. In contrast, when choice is divorced from other aspects of autonomy support, is provided in a way that diminishes feelings of competence, or is incongruent with broader cultural values, the act of choosing is not likely to lead to enhanced motivation, learning, or performance.

We believe that the results of this study are indeed consistent with these perspectives. That is, the success of our homeworkchoices manipulation may be attributed to the fact that it illustrates a good example of how choices can be provided in a way that satisfies fundamental needs. That is, the choice of homework options is likely to have given students an opportunity to engage in the homework task that was reflective of their personal interests and goals. Likewise, feelings of competence may also have been supported in that teachers designed homework options with the intention to provide an optimal level of challenge for students. Further, only two options were provided for each homework task so that student teachers would not be overly burdened by having to design multiple homework versions and so that students would not feel overwhelmed by too many choice options.

Although the experimental results revealed an effect of choice when teachers provided option choices as opposed to action choices related to homework, we agree with Reeve et al. (2003) that this may be an important distinction in deciphering the effects of choice, as well as its relationship with other forms of autonomy support. In looking at the measure of perceived provision of choice that we used in Analysis 2, it is apparent that the questions asked students about the degree to which they believed teachers at school provided both option (e.g. "When the teachers give us an assignment they allow us to choose which questions to answer") and action choices (e.g. "My teachers allow me to choose how to do my work in the classroom"). In fact, five of the eight items clearly were action choices, which may account for why perceived provision of choice was so highly related to intrinsic motivation for schoolwork in our study. In light of the conceptual complexity of 
our baseline measure of choice, we believe that our results are in line with those of previous studies. ${ }^{3}$

However, the results also suggest that whereas providing alternatives to enable the perception that one has choices can be an effective way to support intrinsic motivation, other autonomysupportive practices may be essential for enhancing other dimensions of motivation, including intentions to engage in a task because it is considered valuable, useful, or important. For these other forms of motivation for school tasks, autonomy-supportive practices, such as teacher efforts to take student perspectives; providing opportunities for students to ask questions; or providing rationales for engaging in various tasks may be more effective. This perspective is also in line with those of previous researchers who have suggested that different forms of autonomy support may indeed lead to different motivation-related outcomes (Stefanou et al., 2004). Clearly, our understanding would benefit from future research that teases apart the role of different autonomy-supportive practices in each form of motivation.

In sum, choice may, in part, be effective for enhancing intrinsic motivation because it can also implicate other forms of autonomy support, although, variation in the effects of different types of choices most likely exists. This ability of choice to imply multiple forms of autonomy support may be the source of its powerful effect on intrinsic motivation. This suggests that choice is a critical element in creating an autonomy-supportive environment and not simply an additional input. However, other forms of autonomy support may play a larger role than choice in supporting other forms of motivation, in particular, identified regulation or value for school tasks.

\section{Limitations and Future Research}

A major strength of the experimental manipulation of choice in homework assignments was that it was implemented in actual classrooms, utilized preservice teachers, and required little disruption of the normal school day. Nevertheless, several methodological issues limit the generalizability of our findings. First and most important, missing data in the experimental portion of the study limit the generalizability of the results, particularly to lower achieving students. It is very possible that the provision of homework choices may operate differently for low-achieving students. Though it is unclear and impossible to assess from this study whether the effect of providing choice may be more or less beneficial for low-achieving students, research examining teacher beliefs about providing choice has suggested that teachers believe that choice may be especially beneficial for low-achieving and low-motivation students (Flowerday \& Schraw, 2000).

Second, our intervention was of short duration, and we conducted our study with preservice teachers rather than veteran teachers. It is plausible that implementing choices of homework for a longer duration and by the most experienced and effective teachers might produce a different pattern of results.

Third, the observed effects in this study may have been influenced by the crossover design implemented during the experimental portion of the study. That is, going into the study, all students knew that eventually they would be given or denied a choice of homework assignments. This knowledge may have either strengthened or weakened the observed effects.
Finally, it is important to mention that our results regarding the role of perceived provision of choice in the context of perceptions of other autonomy-supportive practices for intrinsic motivation was based on correlational evidence and should not be taken to imply causation. It is entirely possible that students who are more intrinsically motivated toward schoolwork are also more likely to perceive their teachers as engaging in autonomy-supportive practices and providing choices.

As we have highlighted throughout the discussion, future research can take several directions. First, such research could examine within an experimental context the individual contributions of different types of autonomy-supportive practices in addition to the provision of choice, in order to better tease apart the relative impact of each on various motivational outcomes. To date, most interventions intended to increase teachers' autonomy-supportive behavior have often trained teachers to simultaneously implement multiple strategies and practices meant to support student feelings of autonomy and subsequent motivation. However, it is important that teachers' have specific guidelines as to which practices work best. Future research should work towards isolating the specific teacher behaviors that are most effective in supporting student feelings of autonomy, intrinsic motivation, and other motivation outcomes.

Second, it is important that future research consider the effects of various types of choices, including the action versus options choice differentiation suggested by Reeve et al. (2003) and the extent to which the choices successfully support fundamental needs of autonomy, competence, and relatedness. We suggest that a number of important choice distinctions may exist and should be explored, including the variation in instructional and personal relevance of choices provided and the variation in the potential consequences of choices made.

We would encourage researchers to explore the effectiveness of providing choices across other pedagogical contexts, especially inclass learning. The effects of choice may not be uniform across all domains. Future research might explore how providing students with choices related to the topics, activities, and general classroom procedures during instructional time may impact student motivation for the course.

Likewise, efforts should be made to investigate ways in which the burden placed on teachers of providing students with choices can be reduced. For example, the effectiveness of various tools used to implement homework choices in the classroom, including Internet databases for sharing homework assignments and text-

\footnotetext{
${ }^{3}$ As exploratory analyses, we conducted Analysis 2 after breaking our baseline measure of perceived provision of choice into two scales: one that contained items measuring perceived action choices and the other containing only items measuring perceived option choices. Both perceived action and option choices fully accounted for the relationship between baseline perceived autonomy support and baseline intrinsic motivation for schoolwork. However, the reduction in the coefficient was slightly greater when perceived action choices were added to the model than when perceived option choices were added to the model. This finding lends support to the claims of Reeve et al. (2003) that action choices may indeed be more effective than option choices, although option choices still appear to have a significant relationship with intrinsic motivation. Further, this analysis is limited by the fact that only three items assessed option choices as compared with five items for action choices.
} 
books with end of unit practice options should be investigated both from the student and the teacher perspective.

Finally, as suggested previously, the effects of choice in classrooms should be examined across diverse student populations. Given teachers' anecdotal beliefs that providing choice may be most effective for low-achieving and low-motivation students, future research should systematically examine whether variation in the effects of providing choice in the classroom exists as a function of various student characteristics, including prior academic achievement and prior levels of motivation and perceived competence.

We hope that the findings of this study provide teachers with a practical example of how to apply choice within their classrooms and what its effects might be as well as guide future investigations of how to enhance and support motivation in the classroom.

\section{References}

Assor, A., Kaplan, H., \& Roth, G. (2002). Choice is good, but relevance is excellent: Autonomy-enhancing and suppressing teacher behaviors predicting students' engagement in school work. British Journal of Educational Psychology, 72, 261-278.

Baron, R., \& Kenny, D. (1986). The moderator-mediator variable distinction in social psychological research: Conceptual, strategic, and statistical considerations. Journal of Personality and Social Psychology, 51, 1173-1182.

Bauer, D. J., Preacher, K. J., \& Gil, K. M. (2006). Conceptualizing and testing random indirect effects and moderated mediation in multilevel models: New procedures and recommendations. Psychological Methods, $11,142-163$.

Black, A. E., \& Deci, E. L. (2000). The effects of instructors' autonomy support and students' autonomous motivation on learning organic chemistry: A self-determination theory perspective. Science Education, 84, $740-756$.

Connell, J. P. (1990). Context, self, and action: A motivational analysis of self-system processes across the life span. In D. Cicchetti \& M. Beeghly (Eds.), The self in transition: Infancy to childhood (pp. 61-97). Chicago: University of Chicago Press.

Cooper, H. (1989). Homework. White Plains, NY: Longman.

Cooper, H., Robinson, J. C., \& Patall, E. A. (2006). Does homework improve academic achievement? A synthesis of research, 1987-2003. Review of Educational Research, 76, 1-62.

Cordova, D., \& Lepper, M. (1996). Intrinsic motivation and the process of learning: Beneficial effects of contextualization, personalization, and choice. Journal of Educational Psychology, 88, 715-730.

deCharms, R. (1968). Personal causation. New York: Academic Press.

Deci, E. L. (1971). Effects of externally mediated rewards on intrinsic motivation. Journal of Personality and Social Psychology, 18, 105-115.

Deci, E. L. (1980). The psychology of self-determination. Lexington, MA: Heath.

Deci, E. L., Connell, J. P., \& Ryan, R. M. (1989). Self-determination in a work organization. Journal of Applied Psychology, 74, 580-590.

Deci, E. L., Hodges, R., Pierson, L., \& Tomassone, J. (1992). Autonomy and competence as motivational factors in students with learning disabilities and emotional handicaps. Journal of Learning Disabilities, 25, 457-471.

Deci, E. L., \& Ryan, R. M. (1985). Intrinsic motivation and selfdetermination in human behavior. New York: Plenum Press.

Deci, E. L., \& Ryan, R. M. (1987). The support of autonomy and the control of behavior. Journal of Personality and Social Psychology, 53, $1024-1037$

Deci, E. L., Schwartz, A. J., Sheinman, L., \& Ryan, R. M. (1981). An instrument to assess adults' orientations toward control versus autonomy with children: Reflections on intrinsic motivation and perceived competence. Journal of Educational Psychology, 73, 642-650.
Flowerday, T., \& Schraw, G. (2000). Teacher beliefs about instructional choice: A phenomenological study. Journal of Educational Psychology, 92, 634-645.

Flowerday, T., \& Schraw, G. (2003). Effect of choice on cognitive and affective engagement. Journal of Educational Research, 96, 207-215.

Flowerday, T., Schraw, G., \& Stevens, J. (2004). The role of choice and interest in reader engagement. Journal of Experimental Education, 72, 93-114.

Gottfried, A. E. (1985). Academic intrinsic motivation in elementary and junior high school students. Journal of Educational Psychology, 77, 631-645.

Gottfried, A. E. (1990). Academic intrinsic motivation in young elementary school children. Journal of Educational Psychology, 82, 525-538.

Grolnick, W. S., \& Ryan, R. M. (1987). Autonomy in children's learning: An experimental and individual difference investigation. Journal of Personality and Social Psychology, 52, 977-1077.

Grolnick, W., Ryan, R., \& Deci, E. (1991). The inner resources for school achievement: Motivational mediators of children's perceptions of their parents. Journal of Educational Psychology, 83, 508-517.

Grubbs, F. E. (1950). Sample criteria for testing outlying observations. Annals of Mathematical Statistics, 21, 27-58.

Iyengar, S. S., \& Lepper, M. R. (1999). Rethinking the value of choice: A cultural perspective on intrinsic motivation. Journal of Personality and Social Psychology, 76, 349-366.

Katz, I., \& Assor, A. (2007). When choice motivates and when it does not Educational Psychology Review, 19, 429-442.

Koestner, R., Ryan, R. M., Bernieri, F., \& Holt, K. (1984). Setting limits on children's behavior: The differential effects of controlling versus informational styles on intrinsic motivation and creativity. Journal of Personality, 52, 233-248.

Langer, E. (1975). The illusion of control. Journal of Personality and Social Psychology, 32, 311-328.

Lepper, M. R., Corpus, J. H., \& Iyengar, S. S. (2005). Intrinsic and extrinsic motivational orientations in the classroom: Age differences and academic correlates. Journal of Educational Psychology, 97, 184-196.

Markow, D., Kim, A., \& Liebman, M. (2007). The MetLife survey of the American teacher: The homework experience: A survey of students, teachers, and parents. Retrieved from http://www.eric.ed.gov/ ERICDocs/data/ericdocs2sq1/content_storage_01/0000019b/80/3c/f3/ 74.pdf

McAuley, E., Duncan, T., \& Tammen, V. V. (1989). Psychometric properties of the Intrinsic Motivation Inventory in competitive sport setting: A confirmatory factor analysis. Research Quarterly for Exercise and Sport, 60, 48-58.

Miserandino, M. (1996). Children who do well in school: Individual differences in perceived competence and autonomy in above average children. Journal of Educational Psychology, 88, 203-214.

Overskeid, G., \& Svartdal, F. (1996). Effect of reward on subjective autonomy and interest when initial interest is low. The Psychological Record, 46, 319-332.

Parker, L. E., \& Lepper, M. R. (1992). Effects of fantasy contexts on children's learning and motivation: Making learning more fun. Journal of Personality and Social Psychology, 62, 625-633.

Patall, E. A., Cooper, H., \& Robinson, J. C. (2008). The effects of choice on intrinsic motivation and related outcomes: A meta-analysis of research findings. Psychological Bulletin, 134, 270-300.

Pintrich, P. R., \& De Groot, E. V. (1990). Motivational and self-regulated learning components of classroom academic performance. Journal of Educational Psychology, 82, 33-40.

Raudenbush, S. W., \& Bryk, A. S. (2002). Hierarchical linear models (2nd ed.). Thousand Oaks, CA: Sage.

Reeve, J. (2006). Teachers as facilitators: What autonomy-supportive teachers do and why their students benefit. The Elementary School Journal, 106, 225-236. 
Reeve, J., \& Jang, H. (2006). What teachers say and do to support students' autonomy during a learning activity. Journal of Educational Psychology, 98, 209-218.

Reeve, J., Jang, H., Carrell, D., Jeon, C., \& Barch, J. (2004). Enhancing students' engagement by increasing teachers' autonomy support. Motivation and Emotion, 28, 147-169.

Reeve, J., Nix, G., \& Hamm, D. (2003). Testing models of the experience of self-determination in intrinsic motivation and the conundrum of choice. Journal of Educational Psychology, 95, 375-392.

Reeve, J., \& Robinson, D. T. (1987). Towards a reconceptualization of intrinsic motivation: Correlates and factor structure of the ActivityFeeling Scale. Journal of Social Behavior and Personality, 2, 23-36.

Reeve, J., \& Sickenius, B. (1994). Development and validation of a brief measure of the three psychological needs underlying intrinsic motivation: The AFS scales. Educational and Psychological Measurement, 54, 506-515.

Rubin, D. B. (1987). Multiple imputation for nonresponse in surveys. New York: Wiley.

Ryan, R. M. (1982). Control and information in the intrapersonal sphere: An extension of cognitive evaluation theory. Journal of Personality and Social Psychology, 43, 450-461.

Ryan, R. M., \& Connell, J. P. (1989). Perceived locus of causality and internalization: Examining reasons for acting in two domains. Journal of Personality and Social Psychology, 57, 749-761.

Ryan, R. M., \& Deci, E. L. (2000). Self-determination theory and the facilitation of intrinsic motivation, social development, and well-being. American Psychologist, 55, 68-78.

Ryan, R. M., \& Grolnick, W. S. (1986). Origins and pawns in the classroom: Self-report and projective assessments of individual differences in children's perceptions. Journal of Personality and Social Psychology, $50,550-558$.

Schafer, J. L., \& Graham, J. W. (2002). Missing data: Our view of state of the art. Psychological Methods, 7, 147-177.

Sobel, M. E. (1982). Asymptotic confidence intervals for indirect effects in structural equation models. In S. Leinhardt (Ed.), Sociological methodology 1982 (pp. 290-312). Washington DC: American Sociological Association.

Stefanou, C. R., Perencevich, K. C., DiCintio, M., \& Turner, J. C. (2004). Supporting autonomy in the classroom: Ways teachers encourage student decision making and ownership. Educational Psychology, 39, $97-$ 110.

Swann, W., \& Pittman, T. (1977). Initiating play activity of children: The moderating influence of verbal cues on intrinsic motivation. Child Development, 48, 1128-1132.

Trautwein, U., \& Koller, O. (2003). The relationship between homework and achievement: Still much of a mystery. Educational Psychology Review, 15, 115-145.

Vallerand, R. J., \& Bissonnette, R. (1992). Intrinsic, extrinsic, and amotivational styles as predictors of behavior: A prospective study. Journal of Personality, 60, 599-620.

Vallerand, R. J., Fortier, M. S., \& Guay, F. (1997). Self-determination and persistence in a real-life setting: Toward a motivational model of high school dropout. Journal of Personality and Social Psychology, 72, $1161-1176$

Wellborn, J. G., \& Connell, J. P. (1987). Manual for Rochester Assessment Package for Schools. Unpublished manuscript, University of Rochester, New York.

Williams, G. C., \& Deci, E. L. (1996). Internalization of biopsychosocial values by medical students: A test of self-determination theory. Journal of Personality and Social Psychology, 70, 767-779.

Zuckerman, M., Porac, J., Lathin, D., Smith, R., \& Deci, E. (1978). On the importance of self-determination for intrinsically-motivated behavior. Personality and Social Psychology Bulletin, 4, 443-446.

Received May 23, 2008

Revision received March 8, 2010 Accepted March 18, 2010 